\title{
A Hybrid Approach Based on Multi-Criteria Satisfaction Analysis (MUSA) and a Network Data Envelopment Analysis (NDEA) to Evaluate Efficiency of Customer Services in Bank Branches
}

\author{
Kaveh Khalili-Damghani* \\ Department of Industrial Engineering, South-Tehran Branch, Islamic Azad University, Tehran, Iran \\ Mohammad Taghavi-Fard \\ Department of Industrial Management, Faculty of Management and Accounting, AllamehTabataba'i University, \\ Tehran, Iran \\ Kiaras Karbaschi \\ Department of Management, Iran Banking Education Institute, Tehran, Iran
}

(Received: July 11, 2015 / Revised: December 5, 2015 / Accepted: December 6, 2015)

\begin{abstract}
A hybrid procedure based on multi-Criteria Satisfaction Analysis (MUSA) and a Network Data Envelopment Analysis (NDEA) is proposed to evaluate the relative efficiency of customer services in bank branches. First, a three-stage process including sub-processes such as customer expectations, customer satisfaction, and customer loyalty, is defined to model the banking customer services. Then, fulfillment of customer expectations, customer loyalty level, and the customer satisfaction degree are measured and quantified through a multi-dimensional questionnaire based on customers' perceptions analysis and MUSA method, respectively. The customer services scores and the other criteria such as mean of employee evaluation score, operation costs, assets, deposits, loans, number of accounts are considered in network three-stage DEA model. The proposed NDEA model is formed based on multipliers perspective, outputoriented, and constant return to scale assumptions. The proposed NDEA model quantifies and assesses the total efficiency of main process and assigns the efficiency to customer expectations, customer satisfactions, and customer loyalties sub-processes in bank branches. The whole procedure is applied on 30 bank branches in IRAN. The proposed approach can be used in other organizations such as airports, airline agencies, urban transportation systems, railway organizations, chain stores, chain restaurants, public libraries, and entertainment centers.
\end{abstract}

Keywords: Network Data Envelopment Analysis, Multi-Criteria Satisfaction Analysis, Performance Measurement, Customer Satisfaction Analysis, Bank Performance

* Corresponding Author, E-mail: kaveh.khalili@gmail.com

\section{INTRODUCTION}

Every organization needs to have information about the performance of units and branches that work under its supervision. This is particularly important in banks. Although bank branches do similar jobs, they perform 
differently, because they work in different conditions. Banks are the principal foundation of financial system of every country. Collecting resources, allocating resources, and managing the risks are the main jobs of banks. The environment in which the banks work is very competitive. Therefore, they have to pay an increasing attention to their services and to the way that their resources are allocated.

The efficiency of branches is essential for the continuation of the activities of the whole banking system, because the performance of branches has a direct and systematic impact on the whole banking system (Soteriou and Stavrinides, 1997). The success of organization in properly using inputs and producing more outputs is called efficiency (Borhani, 1999). The efficiency of a bank branch is not solely dependent on operational costs; rather, it is dependent on several other factors such as attracting new customers, offering high-quality services, and creating satisfaction among customers (Grigoroudis et al., 2013). However, the majority of studies, conducted on performance measurement, have focused on financial performance of bank branches. In previous studies, factors related to customer satisfaction have largely been ignored. In the last few decades, the importance of customer satisfaction has continuously been illustrated (Gerson, 1993). Customer satisfaction measurement can help organizations to obtain a clear understanding of customer behavior and to identify their expectations, needs, and tendencies. In addition, it can help us to identify the differences between the views of organizations' managers and the views of customers regarding the quality of services (Motorola, 1995). In an organization such as a bank, customer satisfaction is an undeniable factor in the process of performance measurement (Grigoroudis et al., 2013).

In this study, relative efficiencies of MELLI bank branches are evaluated using both operational data and the customer satisfaction data (i.e., expectations, satisfaction, and loyalty), on the basis of data envelopment analysis (DEA). In order to quantify the data obtained by the questionnaire, a linear programming method called multi-criteria satisfaction analysis (MUSA) is used. In this study, customer expectation is another factor that is included in DEA, because the majority of past studies have ignored this factor in the evaluation process.

The next sections of this paper are organized as follows. In Section 2, a literature of past works are reviewed. In Section 3, the proposed hybrid approach, including criteria for evaluation, MUSA method, and three stage DEA method, are developed. In Section 4, the case study is presented and the results are discussed. Finally, paper will be concluded in Section 5 .

\section{LITERATURE REVIEW}

Decision-making is the main and the most sensitive duty of every manager. The complex and uncertain na- ture of organizational environments makes the process of decision-making difficult. One of the key ways for the improvement of decision-making is the regular and continuous evaluation of main processes of organization. Such evaluations produce useful data by which the process of decision-making in the organization can be facilitated. Performance evaluation has been the subject of discussions from the time that the first classical theories in management were introduced. The importance of regular and continuous evaluation is now clear for all organizations. In order to create a performance evaluation system, those criteria should be selected that show the organizational strategies. These criteria can be keys to success in the current and future activities of the organization.

Farrell (1957) measured the efficiency of a production unit with one input and one output for the first time. The method used by Farrell (1957) was suitable for measuring technical efficiency as well as the efficiency of resource allocation and production function. However, Farrell (1957) was not successful in presenting a method that could include a number of inputs and outputs. Charnes et al. (1978) extended the model proposed by Farrell (1957) and presented a model that could measure efficiency with several inputs and outputs. The model proposed by Charnes et al. (1978) was the first formal data envelopment analysis approach. Banker et al. (1984).

DEA is a non-parametric method based on linear programming that measures the relative efficiency of decision making units (DMUs) with multiple-inputs and multiple outputs. In contrast to parametric methods, in the DEA, there is no need to know the form of production function. Also, there is no limitation in the number of inputs and outputs. DEA attracted lots of attentions and extended increasingly since the seminal work by Charens et al. (1978). The reason for such a great attention was its ability to examine complex and unknown relations among multiple inputs and multiple outputs which were usually unquantifiable.

The evaluation of efficiency in service section has widely been studied in various research works. Evaluating the efficiency of banking institutes has particularly been a key subject for a lot of studies in the US, Europe, and Asia in the past 20 years. The first studies on the evaluation of the performance of firms were based on the capability of the firms to transfer inputs into outputs. However, in these studies, the real processes by which inputs were transferred into outputs were usually ignored (Frei and Harker, 1999).

\subsection{Application of DEA Methods in Banking Industries}

The first study on the evaluation of the efficiency of bank branches by DEA method was conducted by Sherman and Gold (1985). They investigated 14 bank branches of the US. Among these branches, only 6 branches $(42 \%$ of all studied cases) were efficient. Weak 
management, size of the branch, number of employees, and operational costs were reported to be the reasons of inefficiency of other branches. Zenios and Soteriou (1997) studied 144 commercial bank branches in Cyprus. Around $45 \%$ of local deposits were in these branches. In the study, conducted by Zenios and Soteriou (1997), the efficiencies of banking services, profitability, and production of branches were considered. With regard to position, these branches were divided into three groups: urban branches ( 83 branches), rural branches (41 branches), and touristic branches (20 branches). With regard to size, they were divided into three groups: large, medium, and small.

Holod and Lewis (2011) believed that the role of deposits in the past DEA studies was vague, because in some studies deposits were taken as inputs, while in others, they were taken as outputs. Holod and Lewis (2011) suggested a two-stage approach on the basis of a model proposed by Kao and Hwang (2008). In the model proposed by Holod and Lewis (2011), the deposits were taken as intermediate products. In this way, the production approaches and intermediation approaches were evaluated within a unified model. Shyu and Chiang (2012) studied management efficiency of 123 bank branches in Taiwan by a three-stage data envelopment analysis method. Shyu and Chiang (2012) found that the results obtained by three-stage method were significantly different from the results obtained by traditional methods.

Kord et al. (2011) conducted a study in order to determine relative efficiency of bank branches and to offer solutions for improving the efficiency of inefficient branches. In addition, Kord et al. (2011) presented a method for ranking the efficient units by DEA. In their study, the inputs were number of employees, number of terminals, and book value. The outputs were the means of four main deposits and the offered loans. Seventeen bank branches in Sistan and Baluchistan were divided into three groups: grades 3, 4, and 5. Then, the efficiency of these branches was investigated in three consecutive periods. Abrishami et al. (2011) measured the technical efficiency of 12 bank branches in Semnan by an outputoriented DEA approach. They considered four influencing factors: gender of branches' employees, proportion of fixed assets to overall assets, previous financial performance of branches, and financial conditions of the areas in which each branch was located.

Esmaeili and Horri (2014) used the fuzzy data envelopment analysis (DEA) techniques for evaluating and ranking the efficiency of online customer satisfaction index in eight economic banks in Iran.

Kwon and Lee (2015) proposed a DEA-BPNN approach to model a two-stage production process. The proposed model enhanced a two-stage DEA by adding predictive power through artificial neural network. The proposed model was applied data from large U.S. banks. Tsolas and Charles (2015) proposed a DEA model to measure the efficiency of the Greek banks. Stochastic controllable input variable were considered. The pro- posed frontier screened further some of the "best-inclass" banks. Wanke and Barros (2015) proposed a method to is measure the efficiency in Brazilian banking using a two-stage process. They discussed the cost efficiency. Moreover, the policy implications for the Brazilian banking sector were also derived.

Puri and Yadav (2014) proposed a DEA model with undesirable outputs in fuzzy environment. The proposed model calculated the positive cross-efficiencies of each DMU. Performance of banks in India with fuzzy data was measured using the proposed approach. Puri and Yadav (2013) proposed a concept of fuzzy input mix-efficiency and evaluate the fuzzy input mix-efficiency using $\alpha$-cut approach. Moreover, they developed a fuzzy correlation coefficient method using expected value approach which calculates the expected intervals and expected values of fuzzy correlation coefficients between fuzzy inputs and fuzzy outputs. A new method for ranking the DMUs on the basis of fuzzy input mixefficiency was also proposed.

Wang et al. (2014) investigated the relations between the performance of bank holding companies (BHCs) and their intellectual capital (IC). They proposed a two-stage DEA model using fuzzy multiple objective programming approach to calculate the efficiency score. They introduced the benchmark that can be emulated by inefficient BHCs and help BHC managers to develop appropriate strategies needed to enhance their overall efficiency.

Puri and Yadav (2015) proposed a fuzzy DEA to intuitionistic fuzzy DEA (IFDEA) in which the input/ output data were represented by intuitionistic fuzzy numbers (IFNs), in particular triangular IFNs (TIFNs). They illustrated different numerical examples and then compared the results with an existing ranking approach based on geometric average efficiency index. They presented an application of the proposed approach to the banking sector in which two inputs, namely, labour and operating expenses possess intuitionistic fuzzy essence at branch level, and were represented as TIFNs.

Stoica et al. (2015) used DEA and principal component analysis (PCA) to analyze the way in which the financial innovation represented by Internet banking services could contribute to the enhancement of the overall efficiency of Romanian banks. Stoica et al. (2015) applied DEA to compute the aggregate efficiency score for each of the 24 banks. They utilized PCA to classify the banks into different operational strategies groups based on their relative efficiency scores.

Steward et al. (2016) applied a unique data sample to capture the development of the Vietnamese banking sector over the last decade. They examined bank efficiency in Vietnam using DEA. The results of their research indicated that large and very large banks were more efficient than small and medium sized banks with small banks having the lowest efficiency scores in the system.

Wanke et al. (2016) proposed new Fuzzy-DEA $\alpha$ - 
level models to assess underlying uncertainty. Further, bootstrap truncated regressions with fixed factors were used to measure the impact of each model on the efficiency scores and to identify the most relevant contextual variables on efficiency. The proposed models were applied in Mozambican banks to handle the underlying uncertainty.

Khalili-Damghani et al. (2016) presented a comprehensive fuzzy DEA framework for solving performance evaluation problems with coexisting desirable input and undesirable output data in the presence of simultaneous input-output projection. The proposed framework was designed to handle high-dimensional data and missing values. A dimension-reduction method was used to improve the discrimination power of the DEA model and a preference ratio (PR) method was used to rank the interval efficiency scores in the resulting fuzzy environment. A real-life pilot study was presented to demonstrate the applicability of the proposed model and exhibit the efficacy of the procedures and algorithms in assessing emerging markets for international banking.

\subsection{Network DEA Applications}

One of the pitfalls of classic DEA modeling is that the internal process of a DMU is not seen. So, the inefficiency cannot be allocated to sub-process of a DMU. In practice, a DMU may consists of several sub-processes. So, inefficiency of DMU may be the result of inefficiency of some of these sub-processes. The network DEA models were proposed to enhance the aforementioned issue. One of the earliest network structures is two-stage DEA model, in which two serially connected sum-DMUs are assumed to work together in the main DMU. The inputs of the DMU is assumed as inputs of first sub-DMU, the outputs of first sub-DMU, which are called intermediate measure, are assumed as inputs of second sub-DMUs, concurrently. Finally, the outputs of second sub-DMU forms the outputs of main DMU. Figure 1 presents a pure two stage DEA system.

Network data envelopment analysis may include more than two stages (Fare and Grosskopf, 2000). Khalili-Damghani and Taghavifard (2012) proposed a fuzzy two-stage DEA approach for performance measurement in supply chains. They used linguistic terms parameterized with fuzzy sets to model qualitative and vague criteria in their proposed fuzzy two-stage approach designed for agility performance measurement in supply chains.

Khalili-Damghani et al. (2012) used the ordinal Likert-based data in a new two-stage DEA approach for agility performance and illustrated the efficacy of their approach in a supply chain. Khalili-Damghani and Taghavifard (2013) performed sensitivity and stability analysis in two-stage DEA models with fuzzy data. They proposed several models for calculating the stability radius in DEA problems with considerable input and output variations and uncertainties. Khalili-Damghani and Tavana (2013) proposed a new network DEA model for measuring the performance of agility in supply chains. The uncertainty of the input and output data were modelled with linguistic terms and the proposed model was used to measure the performance of agility in a real-life case study in the dairy industry.

Abtahi and Khalili-Damghani, (2011) proposed a mathematical formulation for measuring the performance of agility in supply chains using single-stage fuzzy DEA. Khalili-Damghani et al., (2011) applied the proposed formulation of Abtahi and Khalili-Damghani, (2011) to measure the efficiency of agility in supply chains and used simulation to rank the interval efficiency scores of Abtahi and Khalili-Damghani (2011). Recently, Tavana and Khalili-Damghani (2014) proposed a Stackelberg (leader-follower) game theory approach to prioritize and sequentially decompose the efficiency score of a two-stage structured DMU into a set of efficiency scores for its sub-DMUs. Tavana et al. (2013) proposed a fuzzy group data envelopment analysis model for high-technology project selection at NASA.

\subsection{Non-Financial Criteria in Banking Evaluations}

For many years, the financial criteria of the banks (similar to firms of other industries) were the only criteria by which the performances of the banks were evaluated. However, there are still a lot of firms that rely on financial criteria for evaluating their performance without paying any attention to the deficiencies of such methods. Financial criteria are based on the history and previous performance of a firm. They show the results of management methods and commercial activities without indicating "what is wrong" (McNair et al., 1990). Throughout the past decades, among the main strategies of the banks, the priority has been to use proper policies in order to keep current customers, to strengthen their loyalty, and to maintain a long-term relationship with them. We must bear in mind that the only way to keep the customers is to respond to their needs and expectations and to secure their satisfaction (Grigoroudis et al., 2013).

The measurement of customer satisfaction is one of the key challenges in all commercial organizations that consider it as the main philosophy and the main criterion of performance. Customer satisfaction has been defined in different ways. The usual definitions are based on responding to customers' expectations. Gerson (1993), and Hill (1996) considered satisfaction as a standard for confirming customers' expectations throughout the process of offering goods and services. In other words, satisfaction is based on customers' evaluation of the product and the offered services (Yi, 1991).

Customer satisfaction measurement enables the organizations to analyze customers' needs and expectations within the framework of a connective process. In this way, an organization can enjoy competitive advantage in the market. The "Satisfaction analysis" is more useful than the "satisfaction measurement," because in 
analysis, those factors which have an impact on satisfaction are examined, and a model is made by which the mechanisms of such impacts are analyzed. Customer satisfaction is a result of his/her judgment on an organization's performance. Satisfaction criteria include the quality of products and services as well as other factors that might have an influence on customer satisfaction. Determining the role of these criteria in overall satisfaction function is one of the key points in customer satisfaction analysis. Therefore, a lot of studies have been conducted in order to measure the criteria of customer satisfaction and to examine the ways that these criteria impact on each other in the overall satisfaction function.

The multi-criteria satisfaction analysis (MUSA) was initially introduced by Siskos et al. (1998) and then was discussed by Mehelis et al. (2001). Finally, the comprehensive form of this model was presented by Grigoroudis and Siskos (2010). The aim of this extended model was to measure and analyze customer's satisfaction. MUSA is a scientific-applied method by which the judgments of customers (collected by the questionnaire) are transformed into a linear programming model. By taking into account and combining the judgments of all customers, the degree of customer satisfaction and the importance of various factors of satisfaction are measured. In MUSA technique, customers' judgments are collected by a satisfaction questionnaire. The collected data are transformed into an interval scale. In this way, customer satisfaction is measured and effective factors are identified (Grigoroudis and Siskos, 2010). In MUSA model, it is assumed that overall customer satisfaction is dependent on a set of criteria or service quality, and overall customer satisfaction is determined by a combination of various factors and criteria. Based on the model proposed by Mihelis et al. (2001), customers are asked to express their overall degree of satisfaction and also their satisfaction on the basis of a set of separate criteria.

\subsection{Existing Gap in Previous Researches: Critical Analysis}

Based on the literature review accomplished in this research, it has been recognized that the previous related researches have the following shortcomings:

- Although there are several qualitative approaches in order to measure the customer satisfaction, the quantitative methods in this area have rarely be dis-cussed clearly. Moreover, no application of quantitative customer satisfaction measurement in banking industry has been reported in related literature.

- There are several simple two-stage DEA applications in services, industries, agriculture, production, healthcare, banking, insurance, and economy. While network and three stage DEA models have extensively been developed theoretically, but have seldom been applied in the services, industries, agriculture, production, healthcare, banking, insurance, and economy.
- The combination of a qualitative method in order to measure the customer satisfaction along with threestage network DEA modeling, as well as a meaningful process in which the expectation, satisfaction, and loyalty of customers measured quantitatively have never been addressed in literature of past works.

In this paper, we are going to address all of the above mentioned shortcomings, and to apply the proposed procedure in a real case study in baking industry.

\section{METHODOLOGY}

In this section, first the criteria used in this study, including customer expectations, customer satisfactions, and customer loyalty, and bank branch operational indices are defined and illustrated. Then, the conceptual model of the study is proposed. Afterwards, the MUSA method is discussed. Finally, the proposed three-stage DEA model is presented.

\subsection{Evaluation Criteria}

Employees. This criterion refers to the logarithm of the number of employees of each branch (employees of each branch at the end of financial year 2014). In all three stages of efficiency evaluation, this criterion was used as an input.

Operational costs. This criterion refers to the operational costs of every investigated branch. It is a portion of overall operational costs of selected branches. Operational costs is a widely-used variable in the literature of DEA and efficiency evaluation of bank branches. This is a variable by which the operational efficiency of a bank branch can be judged. It must be noted that operational costs do not include the costs of personnel. In all three stages of efficiency evaluation, this criterion is taken as an input.

The evaluation of employees. This criterion shows the results of the evaluation of employees in each investigated branch. In this study, it is based on the annual evaluation of the employees of MELLLI bank. The data are obtained by calculating the mean of scores of employee evaluation on the basis of a 5-points Likert scale. This parameter has been taken from service-profit chain theory according to which the good performance of an employee is a determining factor for quality of products and services. This parameter is related to meeting customers' expectations and securing their satisfaction. In all three stages of efficiency evaluation, it is used as an input.

Customer expectations. This variable refers to meeting customer expectations and can be obtained by questions 
regarding the degree of customer satisfaction. This parameter is measured on the basis of a 5-points Likert scale. It is obtained by calculating the mean of customers' judgment in each branch. In the efficiency evaluation model of this study, this parameter was taken as the output of the first stage and the input of the second stage.

Deposits. This criterion is one of the commonest parameters in efficiency evaluation of bank branches by DEA. In this study, the value of this parameter was obtained on the basis of figures related to the financial year of 2014. It was a portion of overall deposits of investigated branches. In the efficiency evaluation model of this research, this parameter was taken as the output of the first stage and the input of second stage.

Customer satisfaction. In evaluating the efficiency of bank branches, customer satisfaction is extremely important. This criterion is the result of all customer expectations that are met by bank branches. Customer loyalty is highly reliant on this parameter. The data are collected by customer satisfaction questionnaire. Then, they are analyzed by MUSA method. MUSA method is an ordinal regression model which is based on the principles of multi-criteria decision-making methods. Customer satisfaction is evaluated by taking into account a number of criteria such as variety of services, performance of branches' employees, and degree of access to branches (Mihelis et al., 2001). These data are collected on the basis of satisfaction criteria. Then, they are quantified by MUSA method in a range of $0 \%-100 \%$. In the efficiency evaluation model of the present study, this criterion is taken as the output of the second stage and the input of the third stage.

Offered loans. This criterion is used in many applications of DEA in banking industry. This criterion is usually taken as an output variable. In this study, it is a portion of all offered loans in all investigated branches in the financial year of 2014. In the efficiency evaluation model of this study, this criterion is taken as the output of the third stage.

New current accounts. In the present study, this criterion is based on the figures of financial year 2014. It is a portion of all new current accounts in investigated branches. In the past few years, attracting cheap resources, especially current accounts, has been one of the priorities of Iranian banks. In the efficiency evaluation model of the present study, this criterion is taken as the output of the third stage.

Customer loyalty. The final criterion refers to the loyalty of customers, which is an observable asset for every organization. This criterion is particularly important for banks. The data related to this criterion are collected by a number of questions in customer satisfaction questionnaire. In these questions, customers are asked to name the banks form which they have received services (at most 7 seven banks). Receiving services from a small number of banks shows that the customer is loyal to that small number of banks (Grigoroudis et al., 2013).

\subsection{Conceptual Model of the Research}

In the classical model of DEA, a DMU is taken as the "black box." In this approach, it is assumed that all inputs are simultaneously presented in DMU and all outputs are simultaneously produced by DMU. Although this one-stage approach offers an understanding of internal structure of bank branch, it cannot be investigated the important roles of all effective iterant parameters of the system. Because of cause-effect relationship between various criteria of customer satisfaction (such as expectations and loyalty), a one-stage process cannot be used.

So, in this study, a three-stage network DEA model is suggested in order to handle the relationships among the data of customer satisfaction, employee evaluation, and financial performance. The aim of this model is to evaluate the relative efficiency of every stage of offering services to customers in bank branches. Figure 1 shows the suggested internal structure of a bank branch (i.e., the proposed three stage DMU) in which three levels of services are offered to customers. These levels are taken as decision making sub-units (DMSU):

- DMSU 1 (level 1): customer expectation confirmation

- DMSU 2 (level 2): customer satisfaction performance

- DMSU 3 (level 3): operational results of customer satisfaction

The fundamental logic of this model is based on this assumption that a bank branch puts all its resources (i.e., number of employees, capabilities of employees, and operational costs) together in order to offer its products and services (i.e., deposits, offered loans, and new bank accounts) to customers and to secure their satisfaction (i.e., expectation confirmation, satisfactory performance and loyalty). This three-stage process has been confirmed in several customer behavior analysis model (Oliver, 1997; Varva, 1997; Grigoroudis andSiskos, 2010). According to this theory, customer expectation confirmation is the element by which customer satisfaction is secured. Also, customer loyalty is the direct result of customer satisfaction.

In the model used in this study, it is assumed that the set of deposits function as intermediate measures, because it is one of the outputs of the second stage and one of the inputs of third stage. Therefore, deposits are considered to be the direct results of customer expectation confirmation and a source for the production of products and offering services in bank branches. Also, number of employees, operational costs, and employee evaluation are common inputs in all three stages. The first two variables are the common inputs of DEA models for evaluating the efficiency of bank branches. On the other hand, the evaluation of employees is a criterion 


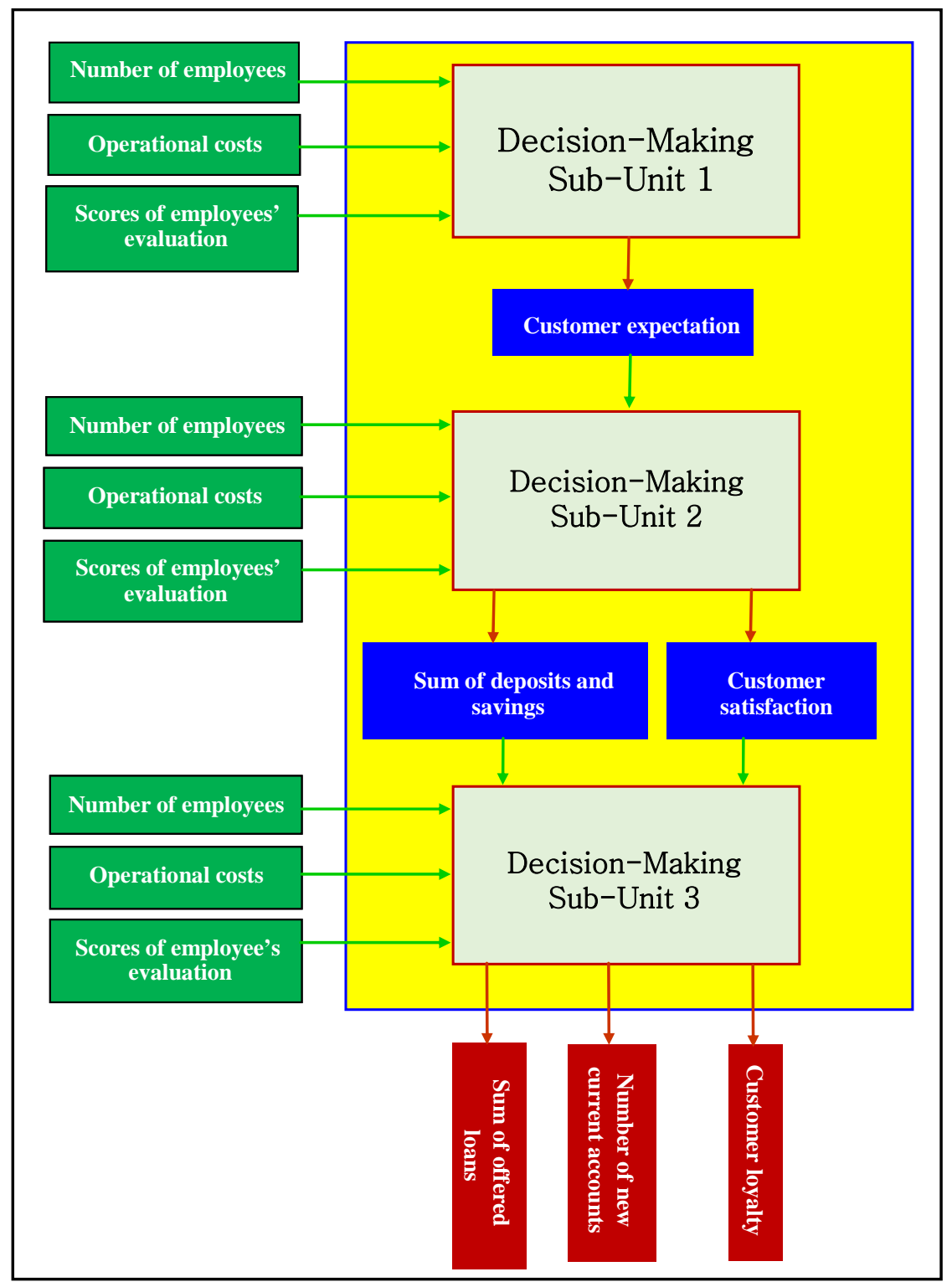

Figure 1. The internal three-stage processes of MELLI bank branches.

for the quality of human resources in service-profit chain approach.

In this model, according to the process shown in Figure 1, the process of offering services in bank branches includes three sub-stages. In each sub-stage, a decision is made on the way that inputs are used as well as their processing (DMSU). In the first sub-process, number of employees of the branch, operational costs of the branch, and evaluation scores of employees produce the outputs or customer expectations. This is a process which is called customer expectation confirmation. In this subprocess, branches cannot produce high-quality product or offer high-quality services without meeting the needs of customers.

In the second sub-process, which is called the evaluation of customer satisfaction performance, the input of customer expectation (produced in the previous stage) and the resources of branch (number of employees, operational costs, employee evaluation) are transformed into the degree of customer satisfaction, which is quantified by MUSA method, and the amount of deposits. It is assumed that these inputs are able to produce more deposits as a direct result of meeting customer needs.

In the third sub-process, which is called operational results and the results of customer satisfaction, the inputs (i.e., degree of customer satisfaction, amount of deposits, number of employees of the branch, operational costs of the branch, and scores of evaluating employees) are transformed into final outputs of the system (i.e., amount of offered loans, the number of new current accounts, and customer loyalty). The first two variables are the commonest outputs in the evaluation of the effi- 
ciency of bank branches by DEA method. In this stage, it is assumed that branch resources, attracted deposits, and customer satisfaction performance are combined together to produce higher operational results and customer loyalty.

If the production process is divided into separate levels, every bank branch has three sub-processes (DMSU) with different input and output variables. The main aim of the model is to find whether each DMSU can properly use its inputs to produce the intended outputs. Also, it aims to find whether the investigated branch (DMU) is able to confirm customer expectations (level 1), to secure customer satisfaction (level 2), and finally to produce good commercial results and to secure customer loyalty (level 3). Therefore, using this model, we can evaluate the efficiency at three levels. It enables us to find whether the overall inefficiency is the result of inefficiency at one level or all levels. Also, it enables us to find which level needs improvement.

\subsection{Multi-criteria Satisfaction Analysis (MUSA) Method}

The main goal of MUSA method is to combine the judgments of customers in a summative function. It is assumed that the overall customer satisfaction is based on a set of $n$ criteria. This set of criteria is shown by $\mathrm{X}=$ $\left(\mathrm{x}_{1}, \mathrm{x}_{2}, \cdots, \mathrm{x}_{\mathrm{n}}\right)$. In this study, five criteria were used for the measurement of customer satisfaction in the banks. These criteria are presented in Table 1.

The customers expressed their degree of overall satisfaction and also their degree of satisfaction on the basis of a set of satisfaction criteria $\left(x_{i}, i=1, \cdots, 5\right)$ as presented in Table 1. This is done by a questionnaire with interval scale as shown in Figure 2.

MUSA method is based on ordinal regression analysis rules. By obtaining the summative function of overall satisfaction $\left(\mathrm{Y}^{*}\right)$ and a set of functions of satisfaction criteria $\left(\mathrm{X}_{\mathrm{i}}^{*}, \mathrm{i}=1, \cdots, 5\right)$, this method tries to create the maximum degree of consistency between overall satisfaction of customers and satisfaction criteria.

The equation of ordinal regression analysis of MUSA has a model in the following form:

$$
\begin{aligned}
& \operatorname{Min} \quad Z=Y^{*}-\sum_{i=1}^{n} b_{i} X_{i}^{*} \\
& \text { s.t. } \\
& \sum_{i=1}^{n} b_{i}=1
\end{aligned}
$$

Where, $\mathrm{Y}^{*}$ and $\mathrm{X}_{\mathrm{i}}^{*}$ have been normalized in [0-100] interval, $b_{i}$ is the weight of criteria $i$. Based on the above-mentioned model and a pair of error variables, ordinal regression equation is in the following form:

Table 1. Criteria of customer satisfaction in bank branches

\begin{tabular}{ccccc}
\hline $\mathrm{X}_{1}$ & $\mathrm{X}_{2}$ & $\mathrm{X}_{3}$ & $\mathrm{X}_{4}$ & $\mathrm{X}_{5}$ \\
\hline Employees of branches & Products (services) & Mental image of bank & Method of offering services & Access to the bank \\
\hline
\end{tabular}

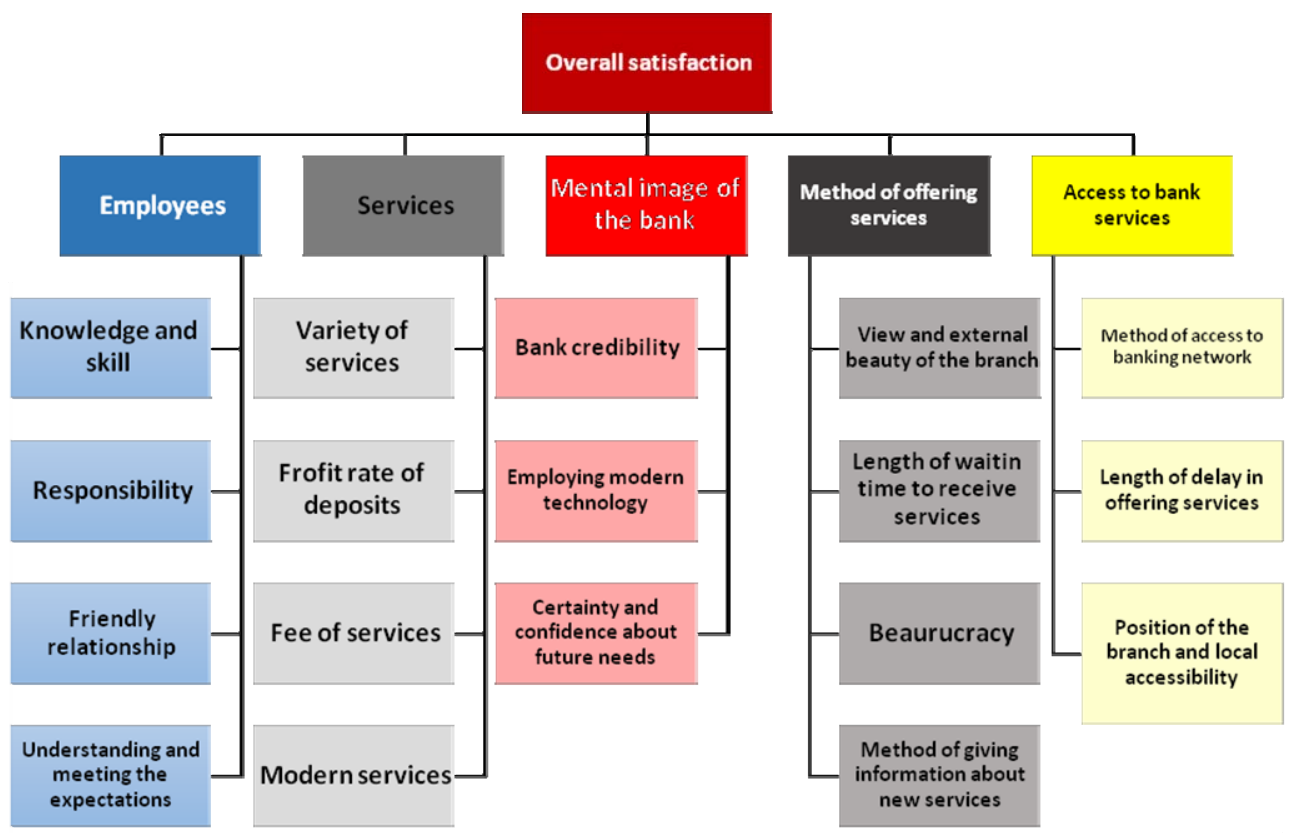

Figure 2. Banking customers' satisfaction hierarchical structure. 


$$
\rho^{\circ}=\sum_{i=1}^{n} b_{i} X_{i}^{*}-\sigma^{+}+\sigma^{-}
$$

Where $Y^{\circ}$ is an estimation of the value of overall function $Y^{*}, \sigma^{+}$and $\sigma^{-}$are the positive and negative deviation variables, respectively. Formula (3) can be used for all customers who have expressed their satisfaction judgments. Therefore, a pair of error variables should be used for every customer separately (Grigoroudis and Siskos, 2010). Table 2 presents all notations used in MUSA modeling approach.

Finally, MUSA model is presented in the following form which is a linear goal programming model. In this model, the sum of deviation variables show the extent to which the combination of satisfaction criteria is different from overall satisfaction for the customer $j$.

$$
\operatorname{Min} F=\sum_{j=1}^{M} \sigma_{j}^{+}+\sigma_{j}^{-}
$$

s.t.

$$
\begin{aligned}
& \sum_{i=1}^{n} \sum_{k=1}^{x_{j}^{i}-1} w_{i k}-\sum_{m=1}^{y^{j}-1} z_{m}-\sigma_{j}^{+}+\sigma_{j}^{-}=0 \\
& \text { for } j=1,2, \mathrm{~L}, M \\
& \sum_{m=1}^{\alpha-1} z_{m}=100 \\
& \sum_{i=1}^{n} \sum_{k=1}^{\alpha_{j}-1} w_{i k}=100
\end{aligned}
$$

$$
\begin{aligned}
& \mathrm{z}_{\mathrm{m}} \geq 0, \forall m \\
& \mathrm{w}_{\mathrm{ik}} \geq 0, \forall i, k \\
& \delta_{j}^{+} \geq 0, \forall j \\
& \delta_{j}^{-} \geq 0, \forall j
\end{aligned}
$$

Because the data collected by the questionnaire are based on an ordinal scale, instead of using the value of responses, the intervals among the options are used. Therefore, zero is assigned to the first option of each question. From the second option to the last option, the interval variable $\left(w_{i k}\right)$ is defined among the options of criterion $i$. Therefore, the last option of criterion $i$ is assigned $(k+1)$ multiplied by $w_{i k}$ (interval variable). The sum of all interval variables in criterion $i$ is taken as $100 \%$. For satisfaction criterion $i$ and overall satisfaction, the measurement scale (between 0 and 100) is normalized. This has been shown in Figure 3.

Based on Figure 3, as can be seen for criterion $i$, if the respondent selects an option between "Complete disagreement" and "Complete agreement", the selection of $w_{i k}$ is proportionate to his/her response. For example, if he/she selects the option of "To some extent agreement" for criterion $i$, the interval value of $w_{i 1}+w_{i 2}$ is used. In the model (4)-(11), for each customer, a constraint is developed. The responses of customer $j$ to all $n$ criteria are included in a linear form, and its deviation from the interval value of overall satisfaction value $\left(\mathrm{z}_{\mathrm{m}}\right)$, which is developed in a way completely similar to the way that $w_{i k}$ is developed, is obtained by the variables of

Table 2. The parameters and variables used in MUSA method

\begin{tabular}{cl}
\hline $\mathrm{Y}$ & \multicolumn{1}{c}{ Overall customer satisfaction } \\
\hline$\alpha$ & Number of levels of overall customer satisfaction $($ response options) \\
\hline$y^{m}$ & Level (option) $m$ in overall satisfaction $(m=1,2, \cdots, \alpha)$ \\
\hline$z_{m}$ & The distance between $m$ and $m+1$ in overall satisfaction \\
\hline $\mathrm{n}$ & The number of satisfaction criteria \\
\hline$x_{i}$ & Partial satisfaction of customer in criterion $i(i=1,2, \cdots, \mathrm{n})$ \\
\hline$\alpha_{i}$ & The number of levels of satisfaction $($ response options) for criterion $i$ \\
\hline$x_{i}^{k}$ & Level (option) $k$ in criterion $i\left(k=1,2, \cdots, \alpha_{\mathrm{i}}\right)$ \\
\hline$w_{i k}$ & The distance between level $k$ and level $k+1$ in criterion $i$ \\
\hline$y^{*}$ & The value of function $y$ \\
\hline$y^{* m}$ & The value of $y^{m}$ (level $m$ in overall satisfaction) \\
\hline$x_{i}^{*}$ & The value of function $x_{i}$ \\
\hline$x_{i}^{* k}$ & The value of $x_{i}^{k}($ level $k$ in criteria $i)$ \\
\hline $\mathrm{M}^{*}$ & Number of customers \\
\hline$y^{j}$ & Option selected by customer $j$ in overall satisfaction $(j=1,2, \cdots, \mathrm{M})$ \\
\hline$x_{i}^{j}$ & Option selected by customer $j$ in criteria $i(j=1,2, \cdots, \mathrm{M})$ \\
\hline$\sigma^{+}$ & The deviation (error) of high estimation \\
\hline$\sigma^{-}$ & The deviation (error) of low estimation \\
\hline
\end{tabular}




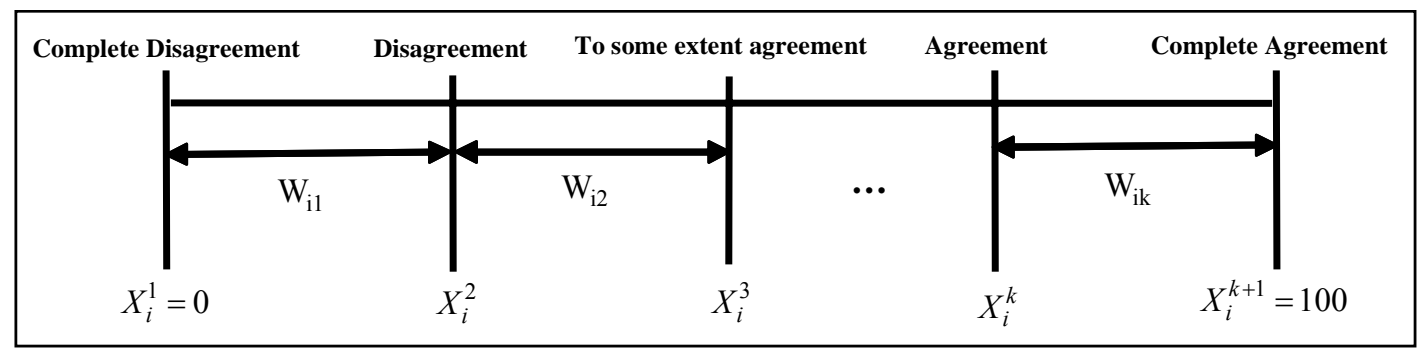

Figure 3. The scales of MUSA model.

"deviation from goal" (i.e., $\sigma_{j}^{+}, \sigma_{j}^{-}$) The aim of the model (4)-(11) is to minimize deviations from the ideal (for all customers) by assigning proper values to measurement scales. In model (4)-(11), $\mathrm{M}$ is the number of customers. The variable $y^{i}$ shows the option selected by customer $j$ for the overall satisfaction criterion, and $\mathrm{x}_{i}^{\mathrm{j}}$ shows the option selected by customer $j$ for criterion $i$. For example, if the fifth customer $(j=5)$ selects "To some extent agreement" for the first criterion $(i=1)$, the value of $x_{i=1}^{j=5}$ is equal to 3. On the other hand, it is the sum of two interval variables of the first criterion $\left(\mathrm{w}_{11}+\mathrm{w}_{12}\right)$.

After solving the model (4)-(11) and finding the optimal values of interval variables, the optimum scale of interval measurement is also obtained. The optimal value of all levels of satisfaction criteria and overall criterion has the minimum deviation from the opinions of all customers. For criterion $i$ at level $k$, the value is calculated using equation $X_{i}^{* k}=100 \sum_{t=1}^{k-1} w_{i t} / \sum_{t=1}^{\alpha_{j}-1} w_{i t}$. For overall satisfaction, it is calculated by equation $Y^{* m}=\sum_{t=1}^{m-1} z_{t}$ (Grigoroudis and Siskos, 2010).

This model (4)-(11) includes $M+2$ constraints and $2 \mathrm{~m}+(\alpha-1)+\sum_{\mathrm{i}=1}^{\mathrm{n}}\left(\alpha_{i}-1\right)$ variables. By creating a systematic approach among satisfaction criteria and overall customer satisfaction, the MUSA method estimates the interval of measurement scale. In addition, it obtains the weights of satisfaction criteria using $b_{i}=$ $\sum_{\mathrm{t}=1}^{\alpha_{\mathrm{i}}-1} \mathrm{w}_{\mathrm{it}} / 100$ equation.

As mentioned, the values of variables are calculated on the basis of optimal answer of model (4)-(11) as follows (Grigoroudis andSiskos, 2010).

$$
\begin{aligned}
& b_{i}=\frac{1}{100} \sum_{t=1}^{\alpha_{t}-1} w_{i t}, \quad i=1,2, \mathrm{~L}, n \\
& y^{*^{*} m}=\sum_{t=1}^{m-1} z_{t}, \quad m=2,3, \mathrm{~L}, \alpha \\
& x_{i}^{* k}=100 \frac{\sum_{t=1}^{k-1} w_{i t}}{\sum_{t=1}^{\alpha_{t}-1} w_{i t}}, \\
& i=1,2, \mathrm{~L}, n ; k=2,3, \mathrm{~L}, \alpha_{i}
\end{aligned}
$$

\subsection{Three-Stage Data Envelopment Analysis Model}

The suggested three-stage data envelopment analysis model of this study is developed in an output-oriented multiplier form with constant return to scale assumptions. The following model is proposed to measure the efficiency score of a three-stage structure.

$$
\begin{aligned}
& \text { Min } \sum_{i=1}^{m} \sum_{s=1}^{3} v_{i}^{s} x_{i o} \\
& \text { s.t. } \\
& \sum_{r_{3}=1}^{k_{3}} u_{r_{3}} y_{r_{3} j}-\sum_{s=1}^{3} \sum_{i=1}^{m} v_{s}^{i} x_{i j} \leq 0, \quad \forall j \\
& \sum_{r_{1}=1}^{k_{1}} u_{r_{1}} y_{r_{1} j}-\sum_{i=1}^{m} v_{i}^{1} x_{i j} \leq 0, \quad \forall j \\
& \sum_{r_{2}=1}^{k_{2}} u_{r_{2}} y_{r_{2} j}-\sum_{i=1}^{m} v_{i}^{2} x_{i j}-\sum_{r_{1}=1}^{k_{1}} u_{r_{1}} y_{r_{i} j} \leq 0, \quad \forall j \\
& \sum_{r_{3}=1}^{k_{3}} u_{r_{3}} y_{r_{3} j}-\sum_{i=1}^{m} v_{i}^{3} x_{i j}-\sum_{r_{2}=1}^{k_{2}} u_{r_{2}} y_{r_{2} j} \leq 0, \quad \forall j \\
& \sum_{r_{3}=1}^{k_{3}} u_{r_{3}} y_{r_{3} o}=1 \\
& \mathrm{v}_{\mathrm{i}}^{\mathrm{s}} \geq \varepsilon, \quad \forall i, \forall s \\
& \mathrm{u}_{\mathrm{j}} \geq \varepsilon \quad \forall j
\end{aligned}
$$

Where, $s$ refers to the level of sub-process or the internal stage of DMU. As mentioned, the DMU of proposed model has three stages $(s=1,2,3)$. It is assumes that each DMUs $(j=1,2, \cdots, n)$ has $m$ inputs $(i=1,2$, $\cdots, \mathrm{m})$ which are shared in all three stages. The definition of other indices, variables, and parameters used in model (15)-(22) is presented in Table 3.

The constraint (16) of model is related to overall efficiency of DMUs. Constraint (17) is related to the efficiency of the first sub-process of DMUs which have $m$ inputs and $k_{l}$ outputs. Constraint (18) is related to the efficiency of the second sub-process of DMUs which have $k_{1}+m$ inputs and $k_{2}$ outputs. As can be seen in Figure 1, outputs of the first stage are inputs of the second stage. The constraint (19) is related to the efficiency of the third sub-process of DMUs which have $k_{2}+m$ inputs 
Table 3. The parameters and variables used in three-stage DEA model

\begin{tabular}{ll}
\hline$m$ & Number of inputs \\
\hline$n$ & Number of DMUs \\
\hline$k_{s}$ & Number of stages \\
\hline$i$ & Number of outputs at stage s \\
\hline$j$ & Index of input $(\mathrm{i}=1, \cdots, \mathrm{m})$ \\
\hline$o$ & Index of DMU $(\mathrm{j}=1, \cdots, \mathrm{n})$ \\
\hline$s$ & Index of DMU under consideration \\
\hline$r_{s}$ & Index of stage $(\mathrm{s}=1, \cdots, \mathrm{S})$ \\
\hline$x_{i j}, i=1, \mathrm{~L}, m ; j=1, \mathrm{~L}, n$ & Index of outputs at stage $\mathrm{s}\left(\mathrm{r}_{\mathrm{s}}=1, \cdots, \mathrm{k}_{\mathrm{s}}\right)$ \\
\hline$y_{r_{s}}, r_{s}=1, \mathrm{~L}, k_{s} ; s=1, \mathrm{~L}, S ; j=1, \mathrm{~L}, n$ & Value of Input $i$ of DMU $\mathrm{j}$ \\
\hline$v_{i}{ }^{\prime}, s=1, \mathrm{~L}, S ; i=\mathrm{L} m$ & Value of Output $r$ at stage $\mathrm{s}$ for DMU $\mathrm{j}$ \\
\hline$u_{r_{s}}, r_{s}=1, \mathrm{~L}, k_{s}$ & Weight of input $i$ at stage $\mathrm{s}$ \\
\hline
\end{tabular}

and $k_{3}$ outputs. It must be noted that the constraints (16)(19) do not allow the efficiency of DMUs and DMSUs to take a value larger than 1 . Finally, the constraint (20) refers to the linearization. Constraints (21)-(22) define the decision variables. In this model, the outputs of the third stage are also assumed as the outputs of DMUs. The $\varepsilon$ is a very small positive value which prevents the decision variables to become zero. Therefore, it prevents the exclusion of input and output variables. After solving the model by LINGO software, the overall efficiency of DMUs is obtained. Using the obtained coefficients and based on the definition of relative efficiency, the efficiency of each sub-process of DMSUs is calculated by equations (23)-(25).

$$
\begin{gathered}
E_{j}^{\mathrm{DMSU}_{1}}=\frac{\sum_{r_{1}=1}^{k_{1}} u_{r_{1}}^{*} y_{r_{1} j}}{\sum_{i=1}^{m} v_{i}^{1^{*}} x_{i j}}, \quad \forall j \\
E_{j}^{\mathrm{DMSU}_{2}}=\frac{\sum_{r_{2}=1}^{k_{2}} u_{r_{2}}^{*} y_{r_{2} j}}{\sum_{i=1}^{m} v_{i}^{2 *} x_{i j}+\sum_{r_{1}=1}^{k_{1}} u_{r_{1}}^{*} y_{r_{1} j}}, \quad \forall j \\
E_{j}^{\mathrm{DMSU}_{3}}=\frac{\sum_{r_{3}=1}^{k_{3}} u_{r_{3}}^{*} y_{r_{3} j}}{\sum_{i=1}^{m} v_{i}^{3^{*}} x_{i j}+\sum_{r_{2}=1}^{k_{2}} u_{r_{2}}^{*} y_{r_{2} j}}, \quad \forall j
\end{gathered}
$$

\section{CASE STUDY AND DISCUSSION OF THE RESULTS}

In this section, the data related to MUSA method and proposed three-stage DEA are presented and discus- sed. Bank MELLI Iran (BMI), is the first national Iranian bank. The bank was established in 1927 by the order of the Iranian Parliament and since then has consistently been one of the most influential Iranian banks. In 1931 the Iranian Parliament authorized the MELLI bank to print and distribute the Iranian currency Rial. BMI acted as the central bank of Iran until Bank MARKAZI was established in 1960, after which all of its central banking responsibilities were transferred to the new central bank. Since 1933, BMI has grown to become a large retail bank with several domestic and international branches. BMI opened its first foreign branch in Hamburg, Germany, in 1965. BMI is now the largest commercial retail bank in Iran and in the Middle East with over 3,300 branches and 43,000 employees. Bank MELLI Iran is owned and operated by the government of Iran. The whole proposed procedure of this study is applied on 30 homogenous branches of MELLI bank in Iran.

According to number of inputs and outputs in the proposed DEA model, this sample fulfills the discrimination conditions for efficiency scores. Twenty questionnaires are distributed among the customers of each branches. Totally 600 questionnaires have been gathered in all 30 branches. The questionnaires contain questions about customer expectations, customer satisfaction, and customer loyalty. Moreover, other operational data (i.e., number of employees, operational costs, score of employee's evaluation, offered loans, new accounts) are collected based on annual reports of each branch. The results of MUSA, as well as three-stage DEA model are presented and discussed in the next sub-sections, respectively. Operational data gathered from bank branches are presented in Table 4.

\subsection{Customer Satisfaction Measurement}

After collecting the data of the customers of 30 MELLI bank branches through questionnaires, MUSA 
Khalili-Damghani, Taghavi-Fard, and Karbaschi: Industrial Engineering \& Management Systems

Table 4. Operational data of bank branches

\begin{tabular}{|c|c|c|c|c|c|}
\hline \multirow{2}{*}{ Branch } & \multirow{2}{*}{$\begin{array}{c}\text { Number of Employees } \\
\text { (Logarithm) }\end{array}$} & \multicolumn{4}{|c|}{ Percentage of Total } \\
\hline & & Operational Cost $^{* *}$ & Deposits $^{* * *}$ & Loans $^{* * * *}$ & New accounts ${ }^{* * * * *}$ \\
\hline B1 & 1 & 0.0141 & 0.0219 & 0.0101 & 0.0154 \\
\hline $\mathrm{B} 2$ & 1 & 0.0256 & 0.0311 & 0.0106 & 0.0444 \\
\hline B3 & 0.9542 & 0.0354 & 0.0401 & 0.0088 & 0.0363 \\
\hline B4 & 1.0792 & 0.0435 & 0.0431 & 0.0314 & 0.0408 \\
\hline B5 & 0.9542 & 0.0916 & 0.0896 & 0.0533 & 0.0389 \\
\hline B6 & 0.9542 & 0.0186 & 0.0243 & 0.0168 & 0.0417 \\
\hline B7 & 1.1139 & 0.0268 & 0.0326 & 0.0185 & 0.0145 \\
\hline B8 & 1.1461 & 0.024 & 0.0291 & 0.0294 & 0.0317 \\
\hline B9 & 0.903 & 0.0447 & 0.023 & 0.0218 & 0.0163 \\
\hline $\mathrm{B} 10$ & 1 & 0.0254 & 0.0245 & 0.0139 & 0.0625 \\
\hline B11 & 0.903 & 0.026 & 0.0328 & 0.0082 & 0.0172 \\
\hline $\mathrm{B} 12$ & 0.845 & 0.0332 & 0.0297 & 0.048 & 0.019 \\
\hline B13 & 1 & 0.0362 & 0.0335 & 0.0392 & 0.0262 \\
\hline B14 & 0.9542 & 0.035 & 0.0262 & 0.0315 & 0.029 \\
\hline $\mathrm{B} 15$ & 0.903 & 0.0332 & 0.0305 & 0.036 & 0.0235 \\
\hline B16 & 1.1461 & 0.0454 & 0.0469 & 0.0429 & 0.0254 \\
\hline B17 & 0.9031 & 0.0312 & 0.0342 & 0.0389 & 0.0199 \\
\hline B18 & 0.8451 & 0.0258 & 0.031 & 0.0373 & 0.0181 \\
\hline B19 & 0.9031 & 0.0297 & 0.0254 & 0.0344 & 0.0163 \\
\hline B20 & 0.9031 & 0.31 & 0.0266 & 0.0296 & 0.0263 \\
\hline B21 & 1.0414 & 0.02 & 0.03 & 0.0381 & 0.039 \\
\hline B22 & 0.9542 & 0.0227 & 0.0335 & 0.0406 & 0.0408 \\
\hline B23 & 1.1139 & 0.0263 & 0.0309 & 0.0389 & 0.0354 \\
\hline B24 & 0.9031 & 0.019 & 0.0268 & 0.0373 & 0.0399 \\
\hline B25 & 0.9542 & 0.0398 & 0.034 & 0.0503 & 0.0462 \\
\hline B26 & 1.0413 & 0.0313 & 0.031 & 0.0457 & 0.0408 \\
\hline B27 & 1 & 0.0214 & 0.0247 & 0.0353 & 0.0389 \\
\hline B28 & 1 & 0.0457 & 0.0361 & 0.0473 & 0.0507 \\
\hline B29 & 0.9031 & 0.0533 & 0.0398 & 0.0541 & 0.0544 \\
\hline B30 & 0.9542 & 0.0429 & 0.0364 & 0.0488 & 0.0526 \\
\hline
\end{tabular}

${ }^{*}$ Log of number of employees per branch.

** Branch operational cost as \% of total cost.

*** Branch deposits as \% of total deposits.

${ }^{* * * *}$ Branch loans as \% of total loans.

****** Number of new bank accounts as \% of total new accounts.

model (4)-(11) was coded and executed in LINGO software. It is notable that a standard questionnaire based on relevant research works by Mihelis et al. (2001) and Grigoroudis et al. (2013) was designed and used in order to collect data of the customers regarding expectation, satisfaction, and loyalty. So, the reliability, verification, and validity of the used questionnaire had been proofed. The applied questionnaire has been presented in Appendix A. The source codes of MUSA method are presented in Appendix B. Table 5 shows the results of customer satisfaction measurement for all investigated branches separately. The branch names cannot be presented due to administrative policies.
Based on the data mentioned in Table 5, the minimum satisfaction is related to B5 (71.32\%) and the maximum satisfaction is related to B29 $(85.62 \%)$. The geometrical means of satisfaction (calculated by MUSA method) of all branches is $76.93 \%$, which is a high score. Also, the mean of expressed customers' satisfaction for all branches is $75.60 \%$.

\subsubsection{The Weights of Satisfaction Aspects by MUSA Method}

One of the applications of MUSA method is the calculation of satisfaction criteria weights in overall satisfaction function. In this method, by minimizing the de- 
Table 5. Results of Customer Satisfaction Measurement by MUSA Method

\begin{tabular}{cccccc}
\hline Branch & Degree of satisfaction & Branch & Degree of satisfaction & Branch & Degree of satisfaction \\
\hline B1 & $\% 75.87$ & B11 & $\% 74.38$ & B21 & $\% 80.66$ \\
\hline B2 & $\% 74.91$ & B12 & $\% 73.42$ & B22 & $\% 81.75$ \\
\hline B3 & $\% 72.01$ & B13 & $\% 72.66$ & B23 & $\% 83.73$ \\
\hline B4 & $\% 71.51$ & B14 & $\% 71.51$ & B24 & $\% 84.08$ \\
\hline B5 & $\% 71.32$ & B15 & $\% 71.81$ & B25 & $\% 83.44$ \\
\hline B6 & $\% 80.23$ & B16 & $\% 74.37$ & B26 & $\% 84.05$ \\
\hline B7 & $\% 81.07$ & B17 & $\% 73.33$ & B27 & $\% 83.46$ \\
\hline B8 & $\% 71.61$ & B18 & $\% 72.65$ & B28 & $\% 83.89$ \\
\hline B9 & $\% 71.60$ & B19 & $\% 71.90$ & B29 & $\% 85.62$ \\
\hline B10 & $\% 78.80$ & B20 & $\% 72.53$ & B30 & $\% 84.81$ \\
\hline
\end{tabular}

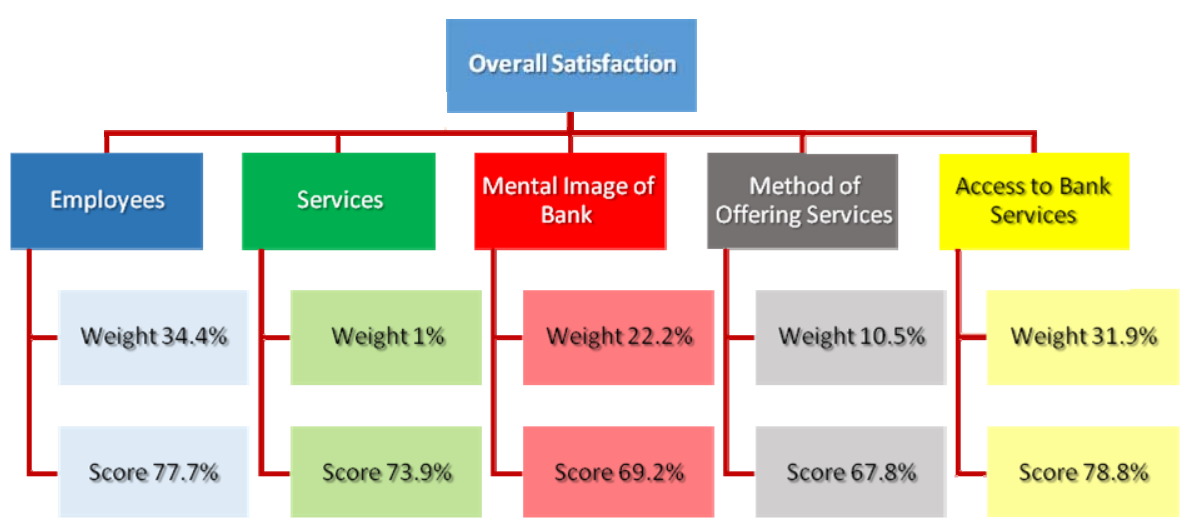

Figure 4. Weights and scores of satisfaction aspects.

viation of the sum of satisfaction criteria from overall satisfaction (expressed by customers), the weight of each satisfaction aspect in overall satisfaction function is determined by taking into account the responses of all customers. Figure 4, presents the criteria weights in the right and those mentioned in the left are related to geometrical means of criteria scores (given by the customers).

In the process of determining overall satisfaction by MUSA method, the maximum weight belongs to bank employees (34.4\%). In other words, the majority of respondents gave a high weight to the criteria of bank employees. The minimum weight belongs to bank services. The majority of respondents expressed their dissatisfaction at modern services (electronic services) and interest rates of MELLI bank deposits. These criteria are assumed to be very important in the banking system and the managerial system should pay enough attention in order to enhance them for competitive aims. Hence, it is necessary for MELLI bank managers to employ effective strategies in order to improve the quality of banking services.

The summarization of customers' expectation, satisfaction, and loyalty are presented in Table 6 .

Both data in Table 4, and Table 6 are used in NDEA model in order to assess the performance of customer services in bank branches.

\subsection{Evaluating the Efficiency of Branches}

The model (15)-(22) is coded in LINGO soft-ware. The source codes of NDEA model are proposed in Appendix $\mathrm{C}$. The optimal weights in DEA were evaluated by the proposed model (15)-(22). In order to obtain the efficiency of DMUs and DMSUs, the Eq. (23)-Eq. (25) were used. Based on the results obtained by the execution of model (15)-(22) and Eq. (23)-Eq. (25), as shown in Table 5, only B1, B21, B22, and B24 were efficient at all three levels of their internal processes. There was not any other branch efficient in one or two DMSUs. Only $\mathrm{B} 1, \mathrm{~B} 21, \mathrm{~B} 22$, and B24 received an overall efficiency score of $100 \%$. Based on the results obtained in this study, a full efficiency can be achieved only when the branch is efficient at all levels of DMSUs.

Branches B1, B21, B22, and B24 managed to meet customer needs (level 1). Among these branches, three branches were in rural areas. In such areas, there is less competition and the number of customers is limited. Table 7 presents the relative efficiency of overall process and each of customer service sub-process.

\subsubsection{Managerial Implications}

Regarding the rest bank branches, the most impor- 
Khalili-Damghani, Taghavi-Fard, and Karbaschi: Industrial Engineering \& Management Systems

Table 6. Customer services data

\begin{tabular}{|c|c|c|c|c|}
\hline DMU & Employee evaluation $^{*}$ & Customer expectations $^{* *}$ & Customer satisfaction $^{* * *}$ & Customer loyalty $^{* * * *}$ \\
\hline $\mathrm{B} 1$ & 3.3 & 3.7333 & 0.7587 & 4.2 \\
\hline B2 & 2.1 & 3.6666 & 0.7491 & 3.8666 \\
\hline B3 & 3.5 & 3.2 & 0.7201 & 3.4666 \\
\hline B4 & 4 & 3.0666 & 0.07151 & 4.9333 \\
\hline B5 & 3.5 & 3.4666 & 0.7132 & 4.1333 \\
\hline B6 & 3 & 3.8666 & 0.8023 & 5.2666 \\
\hline B7 & 3.1 & 3.6666 & 0.8108 & 5.4 \\
\hline $\mathrm{B} 8$ & 3.7 & 3.9333 & 0.7161 & 4.4 \\
\hline B9 & 4.5 & 3.8 & 0.716 & 4.7333 \\
\hline $\mathrm{B} 10$ & 4.1 & 3.9333 & 0.778 & 5.2 \\
\hline B11 & 3.2 & 3.7333 & 0.7438 & 3.9333 \\
\hline $\mathrm{B} 12$ & 2.5 & 3.6 & 0.7342 & 3.2666 \\
\hline $\mathrm{B} 13$ & 3.5 & 3.1333 & 0.7266 & 3.1333 \\
\hline B14 & 3.3 & 3.4 & 0.7151 & 5.1333 \\
\hline $\mathrm{B} 15$ & 2.8 & 3.2666 & 0.7181 & 3.7333 \\
\hline $\mathrm{B} 16$ & 3.6 & 3.8 & 0.7437 & 4.0666 \\
\hline $\mathrm{B} 17$ & 3.8 & 3.9333 & 0.7333 & 3.6666 \\
\hline $\mathrm{B} 18$ & 3.3 & 3.4 & 0.7265 & 3.8666 \\
\hline B19 & 3.7 & 3.2666 & 0.719 & 4.7333 \\
\hline $\mathrm{B} 20$ & 4.3 & 3.4666 & 0.7253 & 0.4 \\
\hline $\mathrm{B} 21$ & 1.3 & 4.4 & 0.8066 & 5 \\
\hline $\mathrm{B} 22$ & 2.6 & 4.333 & 0.8175 & 5.4 \\
\hline $\mathrm{B} 23$ & 3.2 & 4.4666 & 0.8373 & 5.0666 \\
\hline $\mathrm{B} 24$ & 3.9 & 4.2 & 0.8402 & 5.5333 \\
\hline $\mathrm{B} 25$ & 2.9 & 4.2 & 0.8344 & 4.6666 \\
\hline $\mathrm{B} 26$ & 3.4 & 4.1333 & 0.8405 & 4.2666 \\
\hline B27 & 3.7 & 4.2666 & 0.8365 & 4.8 \\
\hline B28 & 3.8 & 4.2 & 0.8389 & 5.3333 \\
\hline B29 & 4.2 & 3.9333 & 0.8562 & 0.5 \\
\hline B30 & 4.1 & 4.6 & 0.8481 & 5.4666 \\
\hline
\end{tabular}

* Average overall evaluation of employees (1-5 scale) gathered by questionnaires.

** Average confirmation of customer expectations (1-5 scale) gathered by questionnaires.

*** Average customer satisfaction index (0-100\% scale) calculated by MUSA method.

${ }^{* * * * *}$ Average number of collaborating banks for branch customers (0-7 scale) gathered by questionnaires.

tant findings are listed as follows.

- Branches B5, B6, B12, B25, and B29 are efficient at levels 2 and 3. However, because of their performance at level 1 (i.e., $99.70 \%, 99.79 \%, 99.86 \%, 99.90 \%$, and $99.64 \%$ ), they did not manage to achieve full efficiency. In other words, these branches did not manage to completely meet customer expectations, although degree of satisfaction of customers and their loyalty is relatively high. In such branches, the rise of customer expectation in a competitive environment could decrease degree of satisfaction among customers as well as their loyalty.

- Branches B2 and B18 are efficient at level 2. Achieving a high level of satisfaction is not based on customer expectation confirmation, and it cannot create high operational results and loyal customers.

- Branches B10 and B30 were efficient at level 3. In other words, they emphasized operational results. These results can be explained by the performance of the branches in area related to new current accounts. The scores of overall efficiency of these branches were relatively high $(99.45 \%$ and $99.64 \%)$. The perform- 
Table 7. Relative efficiency of overall process and each of customer service sub-process

\begin{tabular}{|c|c|c|c|c|}
\hline Branch & Overall efficiency & $\begin{array}{c}\text { First sub-process } \\
\text { (Efficiency of expectations) }\end{array}$ & $\begin{array}{c}\text { Second sub-process } \\
\text { (Efficiency of satisfaction) }\end{array}$ & $\begin{array}{c}\text { Third sub-process } \\
\text { (Efficiency of loyalty) }\end{array}$ \\
\hline B1 & 100.00 & 100.00 & 100.00 & 100.00 \\
\hline B2 & 98.59 & 80.02 & 100.00 & 98.81 \\
\hline B3 & 67.48 & 64.01 & 95.34 & 67.82 \\
\hline B4 & 78.64 & 57.57 & 91.50 & 79.42 \\
\hline B5 & 99.70 & 54.04 & 100.00 & 100.00 \\
\hline B6 & 99.79 & 70.01 & 100.00 & 100.00 \\
\hline B7 & 85.30 & 72.21 & 90.20 & 76.69 \\
\hline B8 & 67.47 & 75.98 & 79.76 & 70.72 \\
\hline B9 & 85.19 & 83.48 & 85.21 & 85.96 \\
\hline B10 & 99.45 & 72.66 & 88.83 & 100.00 \\
\hline B11 & 73.87 & 87.66 & 93.73 & 74.45 \\
\hline $\mathrm{B} 12$ & 99.86 & 92.61 & 100.00 & 100.00 \\
\hline B13 & 74.87 & 66.37 & 93.99 & 75.60 \\
\hline B14 & 91.47 & 75.76 & 91.06 & 92.29 \\
\hline B15 & 79.59 & 78.12 & 91.68 & 82.28 \\
\hline B16 & 71.59 & 71.46 & 75.29 & 80.84 \\
\hline B17 & 83.43 & 89.27 & 89.86 & 83.93 \\
\hline B18 & 90.10 & 83.77 & 100.00 & 90.38 \\
\hline B19 & 87.35 & 74.59 & 94.07 & 88.01 \\
\hline B20 & 73.36 & 76.94 & 92.24 & 73.92 \\
\hline B21 & 100.00 & 100.00 & 100.00 & 100.00 \\
\hline B22 & 100.00 & 100.00 & 100.00 & 100.00 \\
\hline B23 & 82.02 & 88.06 & 90.91 & 83.72 \\
\hline B24 & 100.00 & 100.00 & 100.00 & 100.00 \\
\hline B25 & 99.90 & 95.31 & 100.00 & 100.00 \\
\hline B26 & 93.35 & 85.25 & 93.02 & 94.56 \\
\hline B27 & 88.73 & 92.99 & 94.58 & 89.37 \\
\hline B28 & 95.51 & 87.80 & 93.96 & 95.98 \\
\hline B29 & 99.74 & 87.63 & 100.00 & 100.00 \\
\hline B30 & 99.64 & 94.74 & 90.84 & 100.00 \\
\hline
\end{tabular}

ance of branch B30 at levels 1 and 2 shows that there is a significant progress in customer expectation confirmation and also an increase in customer satisfaction.

- Finally, branches B3, B4, B7, B8, B9, B11, B13, B14, $\mathrm{B} 15, \mathrm{~B} 16, \mathrm{~B} 17, \mathrm{~B} 19, \mathrm{~B} 20, \mathrm{~B} 23, \mathrm{~B} 26, \mathrm{~B} 27$, and B28 were inefficient at all levels of internal processes. They had the lowest overall efficiency score (from $67.48 \%$ to $95.51 \%$ ). All in all, these branches had a relatively low operational performance and low quality services. It must be noted that these branches were located in highly-competitive environments and centers of big cities.
The overall performance of branches at the first level offering services is relatively low, because the mean of overall efficiency scores of first DMSUs is approximately $81.94 \%$. The lowest eight efficiency scores of the first stage belong to those branches which are located in area with high commercial activities and big cities. It must be noted that relative efficiency score in the majority of DMSUs of the first stage (compared to DMSUs of the second and third stages) is low. It shows that the bank is not successful in customer expectation confirmation sub-process. In fact based on Grigoroudis et al., 2013, failure in customer expectation confirma- 
tion can lead to lower operational results, lower customer satisfaction, and lower customer loyalty. This is particularly the case when the branches are working in a highly-competitive environment.

In the second level of service-offering process, the mean of efficiency scores of all DMSUs is $93.87 \%$. Eleven branches are efficient at this level. It must be added that in branches with higher efficiency (such as B10, B26, B28, and B30), the efficiency score of second DMSUs, compared to the efficiency scores of third DMSUs, is lower. Moreover, those branches which have lower efficiency (DMUs of B3, B4, B8, B11, B13, B15, and B20) have a higher efficiency score in the second DMSUs (compared to the third DMSUs). This shows the capability of efficient DMUs in converting the customer satisfaction into high commercial results. It also shows the importance of customer satisfaction in the process of offering services by bank branches.

Finally, the overall performance of DMUs at the third level is relatively high. The overall mean efficiency score of DMSUs is $95.89 \%$. Based on the results of this study, 11 branches (almost one-third of the branches) are efficient at this level. It shows the willingness of investigated bank to achieve high operational results and customer loyalty. The majority of efficient branches were in competitive areas.

Figure 5-Figure 7 show efficiency of pairs of subprocesses. The efficiency scores of the branches in various stages of offering services are shown by vertical and horizontal axis. In this way, they can help the managers of the bank in the process of decision-making. For example, the DMUs of B4, B7, B8, B10, B14, B15, B16, and $\mathrm{B} 20$ are in the below-left quarter of Figures 5. This quarter includes DMUs with the lowest efficiency scores in the first and second. Not only were these branches weak in meeting the needs of customers, but also they performed weakly at the second level of offering services. The results show that a higher level of inputs (particularly employee evaluation) cannot produce a higher level of outputs.

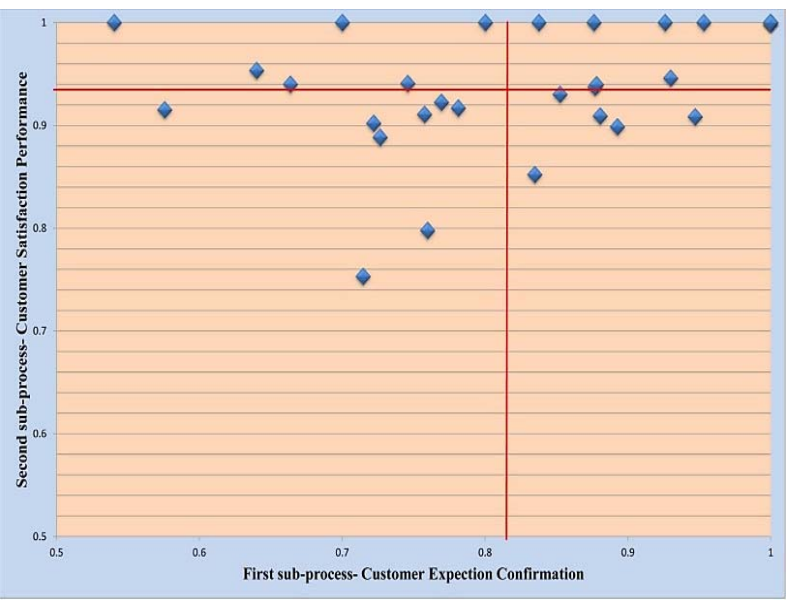

Figure 5. Efficiency of first and second sub-processes.

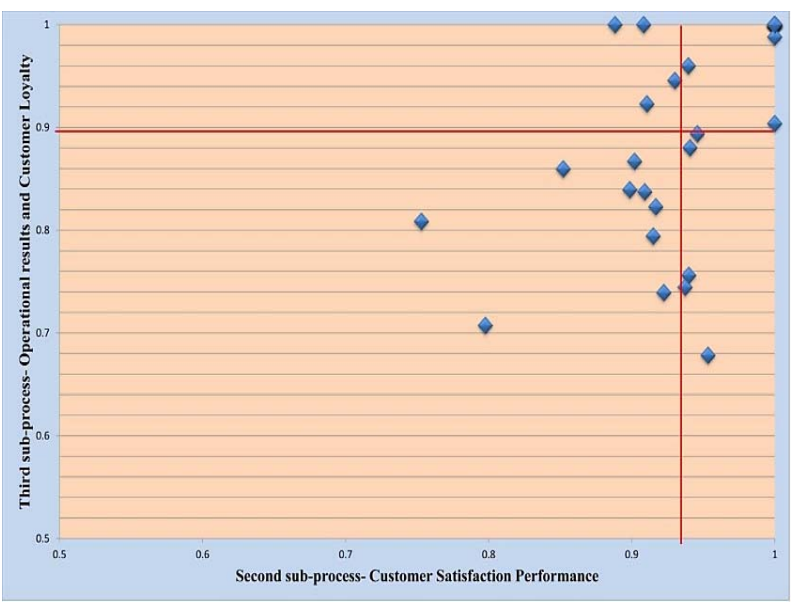

Figure 6. Efficiency of second and third sub-processes.

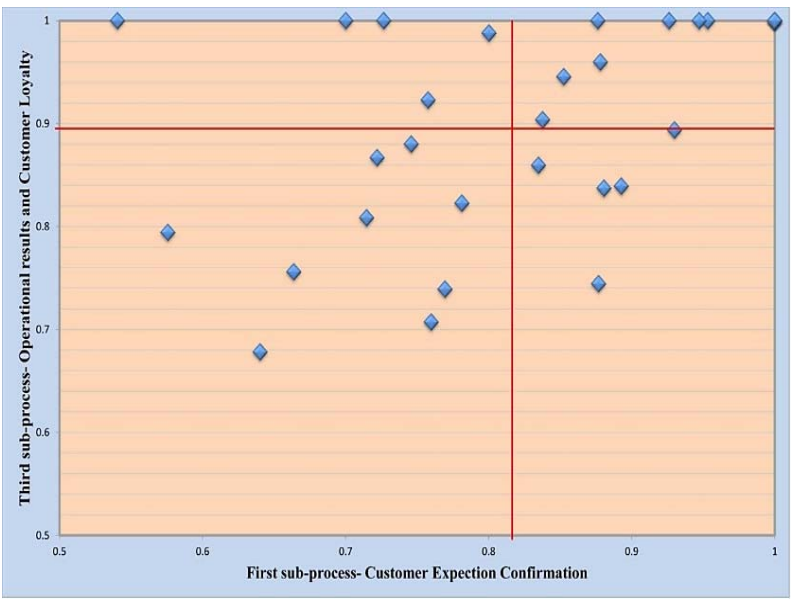

Figure 7. Efficiency of first and third sub-processes.

DMUs of B4, B7, B8, B9, B15, B16, B17, B20, and B23 have the lowest efficiency scores in the second and third DMSUs, because they are in the below-left quarter of Figure $7=6$. Not only did these branches have a weak performance at the second level of offering services, but also they performed weakly in securing customer satisfaction. In addition, the operational results were weak, particularly offered loans and new accounts.

The majority of branches, which have gaps in service-offering in the second and third DMSUs in Figure 6, are a sub-set of DMUs with lowest efficiency scores in first and second DMSUs. It shows that a gap at the first and second levels of the processes of offering services may cause a potential gaps at the third level.

\subsection{Sensitivity Analysis}

A comprehensive sensitivity analysis is conducted in order to making a better sense of the performance of proposed method and the effects of criteria on efficiency score of the system. As depicted in Figure 1, and based on a deep interview with operational managers of bank branches, the operational cost, the scores of employees' 
Table 8. Scenarios of sensitivity analysis

\begin{tabular}{|c|c|c|c|c|c|c|c|}
\hline \multirow{2}{*}{\multicolumn{2}{|c|}{ Scenarios }} & \multicolumn{2}{|c|}{ Operational Cost } & \multicolumn{2}{|c|}{ Employee evaluation } & \multicolumn{2}{|c|}{ Customer satisfaction } \\
\hline & & $10 \%$ Increase & $10 \%$ Decrease & $10 \%$ Increase & $10 \%$ Decrease & $10 \%$ Increase & $10 \%$ Decrease \\
\hline \multirow{6}{*}{$\begin{array}{l}\text { Single } \\
\text { change }\end{array}$} & Scenario 1 & • & & & & & \\
\hline & Scenario 2 & & & • & & & \\
\hline & Scenario 3 & & & & & - & \\
\hline & Scenario 4 & & • & & & & \\
\hline & Scenario 5 & & & & - & & \\
\hline & Scenario 6 & & & & & & $\bullet$ \\
\hline \multirow{8}{*}{$\begin{array}{l}\text { Multiple } \\
\text { change }\end{array}$} & Scenario 1 & - & & • & & - & \\
\hline & Scenario 2 & & • & • & & • & \\
\hline & Scenario 3 & & • & & • & • & \\
\hline & Scenario 4 & & - & & • & & • \\
\hline & Scenario 5 & • & & & • & • & \\
\hline & Scenario 6 & $\cdot$ & & & - & & - \\
\hline & Scenario 7 & • & & • & & & $\bullet$ \\
\hline & Scenario 8 & & • & $\bullet$ & & & $\bullet$ \\
\hline
\end{tabular}

evaluation, and the customer satisfaction were selected for sensitivity analysis. The considered scenarios for sensitivity analysis are summarized in Table 8.

Two main classes of scenarios were planned. In type I, just one of the considered criteria was changed (decreased/increased). The first class of scenarios helped us to recognize the effect of a single change in one criteria on efficiency score of all bank branches in the system. Six scenarios in the first class were considered. In type II, multiple changes of inputs/outputs were considered in order to recognize the synergy and multiple effects of changes of inputs/outputs on efficiency score of the bank branches in the system. Eight scenarios were considered in the second class.

In the all 14 scenarios of sensitivity analysis, two types of changes (i.e., $10 \%$ increase, and $10 \%$ of decrease) are considered using three main inputs/outputs. The proposed three-stage network DEA model was run for all eight scenarios. The results of efficiency scores for type I scenarios (i.e., single change) and type II scenarios (i.e., multiple changes) are presented in Table 9 and Table 10, respectively.

It can be concluded from Table 9 that each of selected criterion has direct effects on efficiency scores. In the last row of Table 9, the average efficiency score for each scenario is presented. It is clear that the maximum average efficiency score is equal to 89.87 and is for 3 scenario in the first class (i.e., single change). This means that the increase of customer satisfaction criterion is the most effective criterion for efficiency of bank branches. The sixth scenario in this class justifies the importance of decrease in customer satisfaction level, as the sixth scenario in which the customer satisfaction has been decreased $10 \%$ in comparison with the original data has the minimum average efficiency score equal to 87.34. Figure 8 presents the average efficiency score of all scenarios in first class.

Table 10 shows the results of efficiency score for multiple change scenarios.

It can be concluded form Table 10 that the increase and decrease in inputs/outputs will change the efficiency score of DMUs (i.e., bank branches). The average of efficiency scores of all branches using original data and all 8 multiple change scenarios, reveal that all of the selected criteria (i.e., the operational cost, the scores of employees' evaluation, and the customer satisfaction) have direct effects on efficiency scores. Moreover, Figure 9 presents the average efficiency scores of multiple change scenarios.

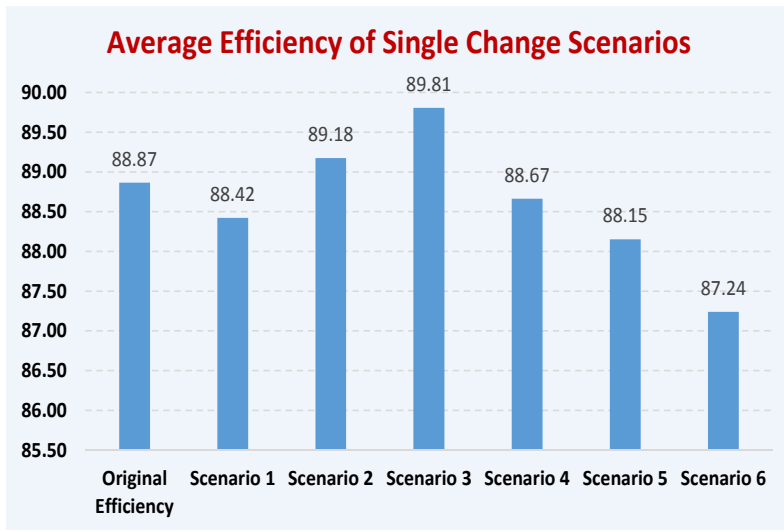

Figure 8. Average efficiency of single change scenarios. 
Khalili-Damghani, Taghavi-Fard, and Karbaschi: Industrial Engineering \& Management Systems

Table 9. Results of sensitivity analysis for first class (single change)

\begin{tabular}{|c|c|c|c|c|c|c|c|}
\hline \multirow{2}{*}{ Branch } & \multirow{2}{*}{$\begin{array}{c}\text { Original } \\
\text { Efficiency }\end{array}$} & \multicolumn{3}{|c|}{ Efficiency of Multiple } & \multicolumn{3}{|c|}{ Single Change Scenarios } \\
\hline & & Scenario 1 & Scenario 2 & Scenario 3 & Scenario 4 & Scenario 5 & Scenario 6 \\
\hline B1 & 100.00 & 99.97 & 100.00 & 100.00 & 100.00 & 98.79 & 99.47 \\
\hline B2 & 98.59 & 98.36 & 99.25 & 100.00 & 98.33 & 96.66 & 97.68 \\
\hline B3 & 67.48 & 67.01 & 67.59 & 69.16 & 67.13 & 66.86 & 67.17 \\
\hline B4 & 78.64 & 78.06 & 78.95 & 79.21 & 77.95 & 78.28 & 76.53 \\
\hline B5 & 99.70 & 99.42 & 100.00 & 100.00 & 100.00 & 98.65 & 96.32 \\
\hline B6 & 99.79 & 99.51 & 100.00 & 100.00 & 100.00 & 98.57 & 99.68 \\
\hline B7 & 85.30 & 84.61 & 85.35 & 87.81 & 85.25 & 84.72 & 84.69 \\
\hline B8 & 67.47 & 67.09 & 67.81 & 67.99 & 66.98 & 67.03 & 65.81 \\
\hline B9 & 85.19 & 84.92 & 85.76 & 87.12 & 84.88 & 84.97 & 83.16 \\
\hline B10 & 99.45 & 98.53 & 99.91 & 100.18 & 98.64 & 99.15 & 97.98 \\
\hline B11 & 73.87 & 73.32 & 74.04 & 74.34 & 73.63 & 73.76 & 73.20 \\
\hline B12 & 99.86 & 99.75 & 100.00 & 100.00 & 100.00 & 98.64 & 99.81 \\
\hline B13 & 74.87 & 74.26 & 75.18 & 76.75 & 74.19 & 73.73 & 72.90 \\
\hline B14 & 91.47 & 90.84 & 92.20 & 93.60 & 90.72 & 90.36 & 87.84 \\
\hline B15 & 79.59 & 79.05 & 79.88 & 79.63 & 79.17 & 79.28 & 77.88 \\
\hline B16 & 71.59 & 71.52 & 72.25 & 72.41 & 70.98 & 70.36 & 69.81 \\
\hline B17 & 83.43 & 83.39 & 84.22 & 83.44 & 82.98 & 83.20 & 81.19 \\
\hline B18 & 90.10 & 89.32 & 90.90 & 92.75 & 90.04 & 88.86 & 87.50 \\
\hline B19 & 87.35 & 87.04 & 87.85 & 89.23 & 86.92 & 87.13 & 86.12 \\
\hline B20 & 73.36 & 73.09 & 73.51 & 74.41 & 73.03 & 72.63 & 73.00 \\
\hline B21 & 100.00 & 99.23 & 100.00 & 100.00 & 100.00 & 98.71 & 99.44 \\
\hline B22 & 100.00 & 99.59 & 100.00 & 100.00 & 100.00 & 98.34 & 98.72 \\
\hline $\mathrm{B} 23$ & 82.02 & 81.66 & 82.04 & 83.98 & 81.75 & 81.94 & 81.77 \\
\hline B24 & 100.00 & 99.89 & 100.00 & 100.00 & 100.00 & 98.64 & 97.54 \\
\hline B25 & 99.90 & 99.28 & 100.00 & 100.00 & 100.00 & 99.48 & 96.18 \\
\hline B26 & 93.35 & 92.87 & 94.23 & 95.67 & 92.67 & 93.21 & 90.98 \\
\hline B27 & 88.73 & 88.53 & 89.30 & 90.05 & 88.04 & 87.27 & 88.68 \\
\hline B28 & 95.51 & 94.76 & 96.13 & 98.29 & 95.10 & 95.12 & 94.10 \\
\hline B29 & 99.74 & 99.17 & 100.00 & 100.00 & 100.00 & 99.47 & 96.82 \\
\hline B30 & 99.64 & 98.72 & 100.00 & 100.00 & 99.26 & 98.19 & 98.33 \\
\hline Average & 88.87 & 88.43 & 89.21 & 89.87 & 88.59 & 88.07 & 87.34 \\
\hline
\end{tabular}

It can be concluded from Figure 9 that the strongest scenario among multiple change scenario is the second

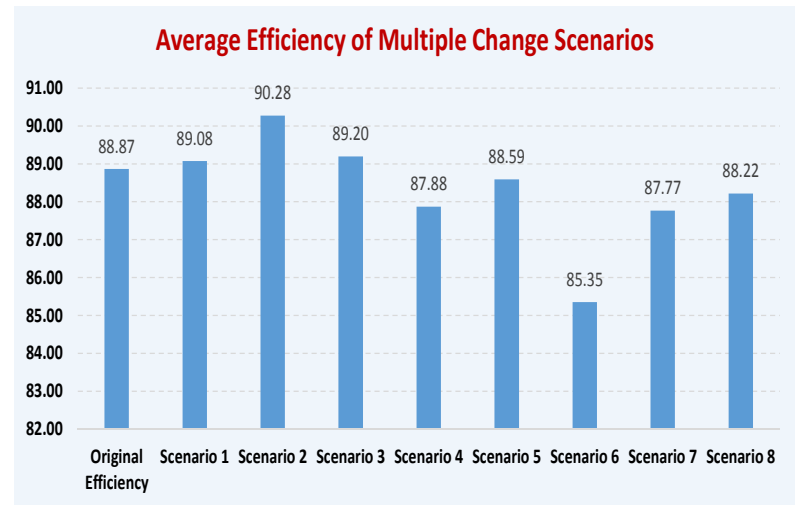

Figure 9. Average efficiency of multiple change scenarios. scenario which leads to an average efficiency score equal to 90.28 . In the second scenario of multiple changes operational cost is decreased by $10 \%$, and both of the employee evaluation and customer satisfaction are increased by $10 \%$ in all bank branches. These scenario supplies the best situation for all DMUs, so the average efficiency score of this scenario has the highest value among from all other scenarios in this class.

It is clear that the sixth scenario in second class which leads to an average efficiency score equal to 85.35 is the weakest scenario. In the sixth scenario of multiple changes operational cost is increased by $10 \%$, and both of the employee evaluation and customer satisfaction are decreased by $10 \%$ in all bank branches. These scenario supplies the worst situation for all DMUs, so the average efficiency score of this scenario has the lowest value among from all other scenarios in this class. 
Table 10. Results of sensitivity analysis for second class (multiple changes)

\begin{tabular}{|c|c|c|c|c|c|c|c|c|c|}
\hline \multirow{2}{*}{ Branch } & \multirow{2}{*}{$\begin{array}{c}\text { Original } \\
\text { Efficiency }\end{array}$} & \multicolumn{8}{|c|}{ Efficiency of Multiple Change Scenarios } \\
\hline & & Scenario 1 & Scenario 2 & Scenario 3 & Scenario 4 & Scenario 5 & Scenario 6 & Scenario 7 & Scenario 8 \\
\hline B1 & 100.00 & 100.00 & 100.00 & 100.00 & 99.54 & 99.85 & 92.59 & 100.00 & 99.74 \\
\hline $\mathrm{B} 2$ & 98.59 & 99.23 & 100.00 & 98.61 & 96.73 & 98.29 & 98.06 & 97.07 & 97.86 \\
\hline B3 & 67.48 & 67.88 & 68.67 & 68.11 & 66.85 & 67.52 & 64.24 & 67.61 & 67.11 \\
\hline B4 & 78.64 & 78.66 & 82.38 & 78.96 & 77.21 & 78.35 & 73.61 & 77.88 & 78.73 \\
\hline B5 & 99.70 & 100.00 & 100.00 & 99.80 & 98.64 & 99.58 & 96.09 & 99.57 & 98.58 \\
\hline B6 & 99.79 & 100.00 & 100.00 & 100.00 & 100.00 & 98.97 & 97.24 & 99.58 & 98.39 \\
\hline B7 & 85.30 & 85.39 & 88.99 & 85.41 & 83.88 & 85.04 & 78.18 & 84.57 & 85.29 \\
\hline B8 & 67.47 & 68.13 & 70.73 & 67.88 & 66.00 & 66.98 & 62.80 & 66.81 & 67.31 \\
\hline B9 & 85.19 & 85.22 & 89.12 & 85.57 & 85.51 & 84.80 & 83.70 & 84.49 & 84.89 \\
\hline $\mathrm{B} 10$ & 99.45 & 100.00 & 100.00 & 100.00 & 98.93 & 99.58 & 92.67 & 98.87 & 97.77 \\
\hline B11 & 73.87 & 73.92 & 74.53 & 73.88 & 72.90 & 73.44 & 71.57 & 71.70 & 73.02 \\
\hline B12 & 99.86 & 100.00 & 100.00 & 100.00 & 97.71 & 99.97 & 93.32 & 98.50 & 98.42 \\
\hline B13 & 74.87 & 74.93 & 75.46 & 75.47 & 74.60 & 74.90 & 71.82 & 74.14 & 74.54 \\
\hline B14 & 91.47 & 91.67 & 92.93 & 92.21 & 89.27 & 90.72 & 87.22 & 90.53 & 90.45 \\
\hline B15 & 79.59 & 79.81 & 81.68 & 80.29 & 79.34 & 79.22 & 77.76 & 78.41 & 78.69 \\
\hline B16 & 71.59 & 71.64 & 75.01 & 72.24 & 71.09 & 71.70 & 66.69 & 70.30 & 71.37 \\
\hline B17 & 83.43 & 83.63 & 84.35 & 84.13 & 81.49 & 83.42 & 79.34 & 82.52 & 82.79 \\
\hline B18 & 90.10 & 90.65 & 93.79 & 90.19 & 88.36 & 89.36 & 87.74 & 87.44 & 90.18 \\
\hline B19 & 87.35 & 87.38 & 89.37 & 87.88 & 86.60 & 87.05 & 83.49 & 86.44 & 86.36 \\
\hline B20 & 73.36 & 74.03 & 73.86 & 73.50 & 71.66 & 73.12 & 72.94 & 72.84 & 73.33 \\
\hline B21 & 100.00 & 100.00 & 100.00 & 100.00 & 99.50 & 99.26 & 100.00 & 98.92 & 100.00 \\
\hline $\mathrm{B} 22$ & 100.00 & 100.00 & 100.00 & 100.00 & 97.93 & 99.82 & 99.96 & 99.71 & 99.23 \\
\hline B23 & 82.02 & 82.17 & 82.65 & 82.71 & 81.46 & 81.97 & 75.81 & 79.72 & 80.98 \\
\hline B24 & 100.00 & 100.00 & 100.00 & 100.00 & 98.29 & 99.28 & 94.11 & 99.27 & 99.35 \\
\hline B25 & 99.90 & 100.00 & 100.00 & 100.00 & 99.88 & 100.00 & 96.14 & 97.31 & 99.34 \\
\hline B26 & 93.35 & 93.44 & 96.74 & 93.93 & 91.34 & 93.02 & 87.93 & 90.79 & 92.15 \\
\hline B27 & 88.73 & 88.83 & 92.42 & 88.82 & 88.19 & 88.52 & 85.62 & 89.16 & 87.77 \\
\hline B28 & 95.51 & 95.71 & 95.63 & 96.35 & 94.72 & 94.92 & 94.30 & 94.46 & 95.13 \\
\hline B29 & 99.74 & 100.00 & 100.00 & 100.00 & 99.69 & 99.58 & 96.38 & 96.59 & 98.51 \\
\hline $\mathrm{B} 30$ & 99.64 & 100.00 & 100.00 & 100.00 & 98.99 & 99.47 & 99.15 & 97.88 & 99.25 \\
\hline Average & 88.87 & 89.08 & 90.28 & 89.20 & 87.88 & 88.59 & 85.35 & 87.77 & 88.22 \\
\hline
\end{tabular}

\section{SUMMARY, CONCLUSIONS, AND SUGGESTIONS FOR FURTHER RESEARCH}

In this paper, a hybrid approach based on multi-criteria satisfaction analysis (MUSA) and a network threestage data envelopment analysis was proposed to measure the efficiency of bank branches. Those processes which lead to the production of financial outputs were investigated by taking into account customer expectation, customer satisfaction, and customer loyalty within the framework of a three-stage process. First, a questionnaire was used to collect data regarding customer satisfaction at offering services. Then, MUSA method was used to determine degree of customer satisfaction (by taking into account their overall views) and also the priorities of effective factors. The data related to cus- tomer satisfaction, customer expectation, and customer loyalty plus the data related to the pervious performance of the branches were entered into data envelopment analysis model as the inputs. The efficiency of sub-processes of customer expectation, customer satisfaction, customer loyalty, and financial performance were measured by a three-stage network data envelopment analysis model. The proposed approach was employed for 30 MELLI bank branches in Iran and the obtained data were analyzed.

One of the innovations of this study was its strategy to quantify and measure customer satisfaction by collecting the judgments of a group of customers. In order to achieve this objective, a multi-criteria satisfaction analysis method was used. Also, the three-stage DEA model separately measured the overall efficiency of each branch as well as the efficiency of sub-processes of customer 
expectation, customer satisfaction, and customer loyalty.

This method can be used in other state and private banks as well as institutes that offer services and goods in a competitive environment. For example, this model can be useful in airports, airline agencies, urban transportation systems, railway organizations, chain stores, chain restaurants, public libraries, and entertainment centers.

Fuzzy criteria are another tool that can be used by researchers in the future studies to quantify and measure satisfaction. The multi-criteria satisfaction analysis model can be developed by fuzzy criteria and the results can be compared with the results obtained in this study. Finally, input-oriented and variable return to scale models can be developed by researchers and their results can be compared with the results obtained by the proposed model of this study.

\section{ACKNOWLEDGEMENT}

This research has been financially supported through a research grant by South-Tehran Branch, Islamic Azad University, Tehran, Iran.

\section{REFERENCES}

Abtahi, A. R. and Khalili-Damghani, K. (2011), Fuzzy data envelopment analysis for measuring agility performance of supply chains, International Journal of Modeling in Operations Management, 1(3), 263-288.

Banker, R. D., Charnes, A., and Cooper, W. W. (1984), Some models for the estimation of technical and scale inefficiencies in Data Envelopment Analysis, Management Science, 30, 1078-1092.

Charnes, A., Cooper, W. W., and Rhodes, E. (1978), Measuring the Efficiency of Decision Making Units, European Journal of Operational Research, 2(6), 429-444.

Esmaeili, A. and Horri, M. (2014), Efficiency evaluation of customer satisfaction index in e-banking using the fuzzy data envelopment analysis, Management Science Letters, 4(1), 71-86.

Färe, R. and Grosskopf, S. (2000), Network DEA, SocioEconomic Planning Sciences, 34 (1), 35-49.

Frei, F. X. and Harker, P. T. (1999), Measuring the Efficiency of Service Delivery Processes: an Application to Retail Banking, Journal of Service Research, 1(4), 300-312.

Gerson, R. F. (1993), Measuring Customer Satisfaction: A guide to Managing Quality Service, Menlo Park: Crisp Publications.

Grigoroudis, E. and Siskos, Y. (2010), Customer Satisfaction Evaluation: Methods for Measuring and Implementing Service Quality, New York: Springer.
Grigoroudis, E., Tsitsiridi, E., and Zopounidis, C. (2013), Linking Customer Satisfaction, Employee Appraisal, and Business Performance: an Evaluation Methodology in the Banking Sector, Annals of Operations Research, 205(1), 5-27.

Holod, D. and Lewis, H. F. (2011), Resolving the Deposit Dilemma: a New DEA Bank Efficiency Model, Journal of Banking and Finance, 35(11), 2801-2810.

Khalili-Damghani, K., Taghavifard, M., Olfat, L., and Feizi, K. (2011), A hybrid approach based on fuzzy DEA and simulation to measure the efficiency of agility in supply chain: real case of dairy industry, International Journal of Management Science and Engineering Management, 6, 163-172.

Khalili-Damghani, K. and Taghavifard, M. (2012), A fuzzy two-stage DEA approach for performance measurement: real case of agility performance in dairy supply chains, International Journal of Applied Decision Sciences, 5(4), 293-317.

Khalili-Damghani, K., Taghavifard, M., Olfat, L., and Feizi, K. (2012), Measuring agility performance in fresh food supply chains: an ordinal two-stage data envelopment analysis, International Journal of Business Performance and Supply Chain Modeling, 4(3/4), 206-231.

Khalili-Damghani, K. and Taghavifard, M. (2013), Sensitivity and stability analysis in two-stage DEA models with fuzzy data, International Journal of Operational Research, 17(1), 1-37.

Khalili-Damghani, K. and Tavana, M. (2013), A new fuzzy network data envelopment analysis model for measuring the performance of agility in supply chains, International Journal of Advanced Manufacturing Technology, doi: 10.1007/s00170-013-5021-y.

Khalili-Damghani, K., Tavana, M., and Santos-Arteaga, F. J. (2016), A comprehensive fuzzy DEA model for emerging market assessment and selection decisions, Applied Soft Computing, 38, 676-702.

Kwon, H.-B. and Lee, J. (2015), Two-stage production modeling of large U.S. banks: A DEA-neural network approach, Expert Systems with Applications, 42(19), 6758-6766.

McNair, C. J., Lynch, R. L., and Cross, K. F. (1990), Do Financial and Non-financial Performance Measures Have to Agree?, Management Accounting, 72(5), 28-36.

Mihelis, G., Grigoroudis, E., Siskos, Y., Politis, Y., and Malandrakis, Y. (2001), Customer Satisfaction Measurement in Private Bank Sector, European Journal of Operational Research, 130(2), 347-360.

Puri, J. and Yadav, S. P. (2013), A concept of fuzzy input mix-efficiency in fuzzy DEA and its application in banking sector, Expert Systems with Applications, 40(5), 1437-1450.

Puri, J. and Yadav, S. P. (2015), Intuitionistic fuzzy data 
envelopment analysis: An application to the banking sector in India, Expert Systems with Applications, 42(11), 4982-4998.

Shyu, J. and Chiang, T. (2012), Measuring the true managerial efficiency of bank branches in Taiwan: A three-stage DEA analysis, Expert Systems with Applications, 39, 11494-11502.

Soteriou, A. and Stavrinides, Y. (1997), An Internal Customer Service Quality Data Envelopment Analysis Model for Bank Branches, International Journal of Operations and Production Management, 17(8), 780-789.

Stewart, C., Matousek, R., and Nguyen, T. N. (2016), Efficiency in the Vietnamese banking system: A DEA double bootstrap approach, Research in International Business and Finance, 36, 96-111.

Stoica, O., Mehdian, S., and Sargu, A. (2015), The Impact of Internet Banking on the Performance of Romanian Banks: DEA and PCA Approach, Procedia Economics and Finance, 20, 610-622.

Tavana, M. and Khalili-Damghani, K. (2014), A new two-stage Stackelberg fuzzy data envelopment analysis model, Measurement, 53, 277-296.

Tavana, M., Khalili-Damghani, K., and Sadi-Nezhad, S. (2013), A fuzzy group data envelopment analysis model for high-technology project selection: A case study at NASA, Computers and Industrial Engineering, 66, 10-23.

Tsolas, I. E. and Charles, V. (2015), Incorporating risk into bank efficiency: A satisficing DEA approach to assess the Greek banking crisis, Expert Systems with Applications, 42(7), 3491-3500.

Vavra, T. G. (1997), Improving Your Measurement of Customer Satisfaction: A Guide to Creating, Conducting and Reporting Customer Satisfaction Measurement Programs, Milwaukee: ASQ Quality Press.

Wang, W.-K., Lu, W.-M., and Liu, P.-Y. (2014), A fuzzy multi-objective two-stage DEA model for evaluating the performance of US bank holding companies, Expert Systems with Applications, 41(9), 4290-4297.

Wanke, P. and Barros, C. (2014), Two-stage DEA: An application to major Brazilian banks, Expert Systems with Applications, 41(5), 2337-2344.

Wanke, P., Barros, C. P., and Emrouznejad, A. (2016), Assessing productive efficiency of banks using integrated Fuzzy-DEA and bootstrapping: A case of Mozambican banks, European Journal of Operational Research, 249, 378-389.

Yadav, S. P. and Puri, J. (2014), A fuzzy DEA model with undesirable fuzzy outputs and its application to the banking sector in India, Expert Systems with Applications, 41(14), 6419-6432. 


\section{Appendix A. Expectation, Satisfaction, and Loyalty Questionnaire}

\begin{tabular}{|c|c|c|c|c|c|c|c|}
\hline \multicolumn{8}{|c|}{ 1: Completely adverse; 2: Adverse; 3: Indifferent; 4: Agreed; 5: Completely Agreed } \\
\hline Theme & & Questions & 1 & 2 & 3 & 4 & 5 \\
\hline Expectation & 1 & My expectations from a bank branch are met in this branch well & $\bullet$ & $\bullet$ & $\bullet$ & $\bullet$ & $\bullet$ \\
\hline \multirow{5}{*}{ Personnel } & 2 & The personnel are knowledgeable and skilled & $\bullet$ & $\bullet$ & $\bullet$ & $\bullet$ & $\bullet$ \\
\hline & 3 & The personnel are responsible & $\bullet$ & $\bullet$ & $\bullet$ & 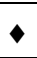 & 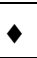 \\
\hline & 4 & The relationship of you and the personnel of the Bank is friendly & $\bullet$ & $\bullet$ & $\bullet$ & 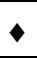 & 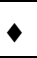 \\
\hline & 5 & The personnel can understand and satisfy your needs & $\bullet$ & $\bullet$ & $\bullet$ & $\bullet$ & $\bullet$ \\
\hline & 6 & Globally, you are satisfied with the overall performance of the personnel & $\bullet$ & $\bullet$ & $\bullet$ & $\bullet$ & $\bullet$ \\
\hline \multirow{5}{*}{$\begin{array}{c}\text { Products and } \\
\text { Services }\end{array}$} & 7 & The variety of offered products and services is large & $\bullet$ & $\bullet$ & $\bullet$ & $\bullet$ & $\bullet$ \\
\hline & 8 & The level of provided interest rate is satisfactory & $\bullet$ & $\bullet$ & $\bullet$ & 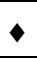 & 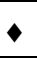 \\
\hline & 9 & The cost charge of provided products and services is satisfactory & $\bullet$ & $\bullet$ & $\bullet$ & $\bullet$ & $\bullet$ \\
\hline & 10 & The bank's especial products and services are satisfactory & $\bullet$ & $\bullet$ & $\bullet$ & $\bullet$ & $\bullet$ \\
\hline & 11 & Globally, the satisfaction level from provided products and services is high & & $\bullet$ & $\bullet$ & $\bullet$ & 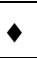 \\
\hline \multirow{4}{*}{$\begin{array}{l}\text { Customer } \\
\text { Image }\end{array}$} & 12 & The bank has enough credit in customers' opinion & $\nabla$ & $\bullet$ & $\bullet$ & $\bullet$ & $\bullet$ \\
\hline & 13 & The bank uses the novel technologies in presenting products and services & $\nabla$ & $\bullet$ & $\bullet$ & $\bullet$ & $\bullet$ \\
\hline & 14 & The bank can satisfy the future needs of customers & 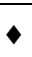 & $\bullet$ & $\bullet$ & $\bullet$ & $\bullet$ \\
\hline & 15 & Globally, the image of the bank is positive in customers' opinion & 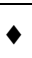 & $\bullet$ & $\bullet$ & $\bullet$ & $\bullet$ \\
\hline \multirow{5}{*}{ Services } & 16 & The appurtenance of the branches are satisfactory & $\bullet$ & $\bullet$ & $\bullet$ & $\diamond$ & $\bullet$ \\
\hline & 17 & The average waiting time is low & $\nabla$ & $\bullet$ & $\bullet$ & $\bullet$ & $\bullet$ \\
\hline & 18 & The processes in the bank are not bureaucratic & $\nabla$ & $\bullet$ & $\bullet$ & 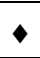 & $\bullet$ \\
\hline & 19 & The information you received form the bank is complete & $\nabla$ & $\bullet$ & $\bullet$ & 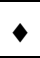 & $\bullet$ \\
\hline & 20 & Globally, the services of bank are satisfactory & $\nabla$ & $\bullet$ & $\bullet$ & $\diamond$ & $\bullet$ \\
\hline \multirow{4}{*}{ Access } & 21 & The bank's network (ATM, branch, etc) is developed & $\nabla$ & $\bullet$ & $\bullet$ & $\bullet$ & $\bullet$ \\
\hline & 22 & The systems of the bank (ATM, e-bank, soft-wares, etc) rarely appear troubles & & $\bullet$ & $\bullet$ & $\bullet$ & $\bullet$ \\
\hline & 23 & The locations of the branches are suitable and convenient & $\nabla$ & $\bullet$ & $\bullet$ & $\bullet$ & $\bullet$ \\
\hline & 24 & Globally, the satisfaction level of provided ability to access the bank is high & $\nabla$ & $\bullet$ & $\bullet$ & $\bullet$ & $\bullet$ \\
\hline $\begin{array}{c}\text { Overall } \\
\text { Satisfaction }\end{array}$ & 25 & Taking into account, all above questions, the overall satisfaction is high & & $\bullet$ & $\bullet$ & $\bullet$ & $\bullet$ \\
\hline \multirow{2}{*}{ Loyalty } & 26 & I replace another bank in the near future to receive more reliable services & 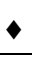 & $\bullet$ & $\bullet$ & $\bullet$ & $\bullet$ \\
\hline & 27 & The number of other banks which I'm receiving services from is high & & $\bullet$ & 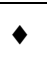 & $\bullet$ & $\diamond$ \\
\hline
\end{tabular}




\section{Appendix B. Source LINGO Codes for MUSA Method}

MODEL:

SETS:

CRITERIA/ $1 \cdots 5 /: \mathrm{B}$

CUSTOMER/1 $\cdots$ 450/: SIGMAP, SIGMAN, Y;

LINK2 (CUSTOMER, CRITERIA): X;

ENDSETS

DATA:

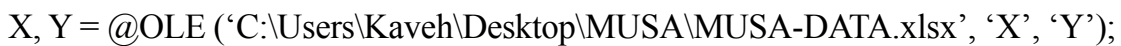

(@) OLE ('C: $\backslash$ Users $\backslash$ Kaveh $\backslash$ Desktop\MUSA \MUSA-DATA.xlsx', 'B') = B;

ENDDATA

SUBMODEL OBJECTIVE:

$\mathrm{MIN}=\mathrm{F}$;

$\mathrm{F}=@ \operatorname{SUM}(\mathrm{CUSTOMER}(\mathrm{J}):$ SIGMAP (J)+SIGMAN (J));

ENDSUBMODEL

SUBMODEL CONSTRAINT:

@.FOR (CUSTOMER(J):

Y(J)-@SUM(CRITERIA (I): B (I) ×X (J, I))+SIGMAP (J)-SIGMAN $(\mathrm{J})=0$;

) ;

@SUM (CRITERIA (I): B (I)) =1;

@FOR (CRITERIA (I):

$\mathrm{B}(\mathrm{I})>0.01$;

);

ENDSUBMODEL

CALC:

@SOLVE (OBJECTIVE, CONSTRAINT);

ENDCALC

END 


\section{Appendix C. Source LINGO Codes for NDEA Method}

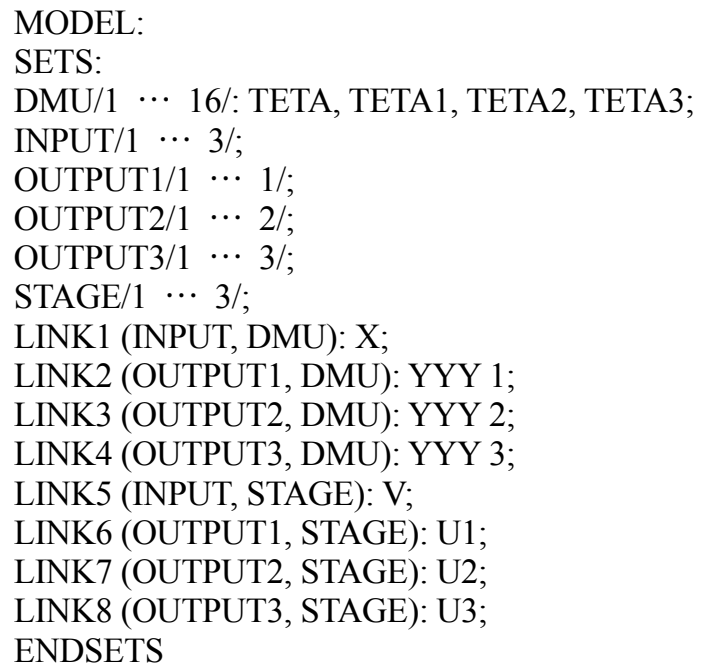


)

@FOR (STAGE (S):

@)FOR (INPUT(I): V (I, S) >=0;

);

@)FOR (OUTPUT1 (R): U1 (R, S) >= 0.001;

);

@ FOR (OUTPUT2 (R): U2 (R, S) >= 0.001;

);

@)FOR (OUTPUT3 (R): U3 (R, S) >= 0.001;

) );

! $* * * * * * * * * * * * * * * * * * * * * * * * * * * * * * * * * * * * * * * * * * * * * * * * * * * * * * * * * * * * * * * * * * * * * * * * * * * * * * * * * * * * * * * * * * * * * * * *$

$* * * * * * * * * * * * * * * * * * * * * * * *$;

!INPUT-OUTPUT ORIENTATION CONSTRAINTS;

![OUTPUTORIENTED]; !@SUM(OUTPUT3 (R): U3 (R, 3)×YYY3 (R, O))=1;

![INPUTORIENTED]; @SUM (INPUT (I): @SUM (STAGE (S): V (I, S) $\times \mathrm{X}(\mathrm{I}, \mathrm{O}))$ )=1;

!********************************************************************************************************

$* * * * * * * * * * * * * * * * * * * * * * * *$;

!CALCULATION OF SUB-EFFICIENCIES NON-LINEAR PROGRAMMING;

!STAGE1;

TETA1 (O)=@SUM (OUTPUT1(R): U1 (R, 1)×YYY1 (R, O))/@SUM (INPUT(I): V (I, 1)×X (I, O));

!STAGE2;

TETA2 (O) = @SUM (OUTPUT2(R): U2 (R, 2)×YYY2 (R,O))/(@SUM (INPUT(I): V (I,2)×X (I, O))

$+@$ SUM(OUTPUT1 (R): U1(R, 1)×YYY1 (R, O)));

!STAGE3;

TETA3 (O)=@SUM (OUTPUT3 (R): U3 (R, 3)×YYY3 (R, O))/(@SUM (INPUT(I): V (I, 3)×X (I, O))

+@SUM (OUTPUT2 (R): U2 (R, 2)×YYY2 (R, O)));

ENDSUBMODEL

\section{CALC:}

$\mathrm{O}=0$;

@WHILE( O \#LT\#@SIZE (DMU):

$\mathrm{O}=\mathrm{O}+1$

@SOLVE (OBJECTIVE, CONSTRAINT);

!@PAUSE ( );

);

ENDCALC

END 